Review Article

\title{
Study on Some Mechanical and Chemical Properties of Agro Residual Briquettes Produced from Date Palm Fronds
}

\author{
Ayman Hafiz Amer Eissa ${ }^{1}$, Abdul Rahman Othman Alghannam ${ }^{2}$ \\ ${ }^{1}$ Agriculture Engineering Department, Faculty of Agriculture, Menoufia University, Shibin El-Kom, Egypt \\ ${ }^{2}$ Bio-Environmental Engineering Dept., Natural Resources and Environmental Research Institute, King Abdulaziz City for Science and \\ Technology, Riyadh, Saudi Arabia
}

Email address:

ayman.amer@agr.menofia.edu.eg(A.H. A. Eissa)

\section{To cite this article:}

Ayman Hafiz Amer Eissa, Abdul Rahman Othman. Alghannam. Study on Some Mechanical and Chemical Properties of Agro Residual Briquettes Produced from Date Palm Fronds. International Journal of Science and Qualitative Analysis. Vol. 4, No. 2, 2018 , pp. $42-59$. doi: $10.11648 /$ j.ijsqa.20180402.13

Received: December 8, 2017; Accepted: February 11, 2018; Published: April 23, 2018

\begin{abstract}
The agricultural crop residuals are considered one of the most important problems, which face the environmental life and farmers in the world. A study was carried out to evaluate the physical characteristics of chopped date palm stalks (fronds and leaflets). These properties are necessary to apply normal design procedures such as pneumatic conveying, fluidization, drying, and combustion. The mechanical treatment by cutting, crushing or chopping and briquetting processes are the primary step and the suitable solution for solving this problem and recycling these residuals to be transformed into useful products. So the aim of the present work to get a high quality for agriculture residues such as date palm stalks (Fronds), date palm leaflets briquettes. The results obtained from measuring the mechanical properties (average shear and compressive strength) for date palm stalks at different moisture content $(12.63,33.21$ and $60.54 \%)$ was $(6.4,4.7$ and $3.21 \mathrm{MPa})$ and $(3.8,3.18$ and $2.86 \mathrm{MPa})$ respectively. The modulus of elasticity and toughness were evaluated as a function of moisture content. As the moisture content of the stalk regions increased the modulus of elasticity and toughness decreased indicating a reduction in the brittleness of the stalk regions. Chopped date palm stalks (Palm fronds), date palm leaflets having moisture content $(8,10$ and $12 \%)$ and $(8,10$ and $12.8 \%$ w.b.) were dandified into briquettes without binder and with binder (Urea-Formaldehyde) using a screw press machine. Quality properties for briquettes were durability, compression ratio hardness, bulk density, compression ratio, resiliency, water resistance and gases emission. The optimum quality properties found for briquettes at $8 \%$ moisture content and without binder. Where the highest compression stress and durability were 8.95, $10.39 \mathrm{MPa}$ and $97.06 \%, 93.64 \%$ for date palm stalks (Palm fronds), date palm leaflets briquettes, respectively. The $\mathrm{CO}$ and $\mathrm{CO}_{2}$ emissions for date palm stalks (Fronds), date palm leaflets briquettes were less than these for loose residuals.
\end{abstract}

Keywords: Residues, Date Palm Stalks, Physical Properties, Chopper, Briquetting, Quality Properties

\section{Introduction}

Date palm (Phoenix dactylifera L.) is one of the most important comerical crops and plays an important role in the economic and social lives of the people of Egypt and Saudi Arabia. The fruit is composed of a seed and fleshy per carp which constitutes between $85 \%$ and $90 \%$ of date fruit weight. In Saudi Arabia, the mean annual yield production of date fruits is about 1,122,822 (MT) from area harvested 172297 (Ha), and Egypt is 1373570 (MT) is classified as one of the first states in the global production of dates (FAOSTAT, 2011). The cultivation of date palm its use in the textile industry has been practiced in Saudi Arabia since pre-historic times.

Worldwide, there are approximately 105 million palm trees covering an area of 800, 000 ha (Agoudjil et al., 2011). As an average, 13 leaves and 7 bunches per date palm could be cut annually. The calculated amount of the date palm recovered material was estimated to be over than 1,200,000 tons of fronds; 410,000 tons of leaves and 300, 000 tons of bunches were produced annually. In Saudi Arabia alone, approximately 
100, 000 tons of date palm fronds and 15, 000 tons of date palm leaves were produced annually (Al-Sulaiman, 2003). However, the bulk of this material is discarded as waste. The efficient utilization of this natural resource would have a positive impact on Saudi fragile environment and may help to preserve it (Al-Sulaimann, 2003). Disposal of farm residues are one of the main problems facing Egyptian farmers which estimates about 30-35 million ton/year (Shaban and Sawan, 2010). Date stalk is considered as the one of the main environmental problems in Egypt and Saudi. Date trees produce large quantities of agricultural waste and according to one estimate, each date tree produces about $20 \mathrm{~kg}$ of dry leaves yearly. Other wastes such as date pits represent an average of $10 \%$ of the date fruits. Although these agriculture wastes consist of cellulose, hemicelluloses, lignin and other compounds which could be used in many biological processes, they were burned in farms causing a serious threat to the environment. Although several investigators have studied date palm cultivation, their utilization and scope for utilizing date fruit in therapeutic applications, reviews available in the literature are rather limited to the chemistry and pharmacology of the date fruits (Baliga et al. 2011).

Biomass is considered one of the main renewable energy resources of the future due to its large potential, economic viability and various social and environmental benefits. It was estimated that by 2050 biomass could provide nearly $38 \%$ of the world's direct fuel use and $17 \%$ of the world's electricity (Demirbas, 2000). The briquetting technology improves the characteristics of agro-residues for transportation, storage, feeding into furnaces, and combustion (Werther, et al 2000). The mechanical strength of the briquettes can be improved by adding some biomass samples. For example, the presence of paper mill waste increased the shatter index of the briquettes obtained. Similarly, sawdust and paper mill waste increased compressive strength of the briquettes. Water resistance of the briquettes can be augmented by adding olive refuse, cotton refuse, and pine cone or paper mill waste (Yamnan, et al 2001) To produce high quality pellets, the feedstock has to be dried to a moisture content of about $10 \%$ (raw weight). Since it is not possible to reach such low moisture contents by natural drying, the material has to be artificially dried. However, a wide range of temperatures and retention times can be used in the drying process (Stahl, et al 2004). To improve the quality of the briquettes and to have an economically competitive product at the same time, the esparto was partially pyrolyzed at temperatures between $160^{\circ} \mathrm{C}$ and $400^{\circ} \mathrm{C}$, and the pressure of densification has been examined. The combustion profile of the samples has been studied by applying the derivative thermogravimetry technique and the mechanical properties of the briquettes were tested to evaluate the impact resistance and water resistance (Debdoubi, et al 2005). To make the biomass materials available for a variety of applications, the challenges with the use of biomass materials in their original form must be resolved. Because of high moisture content, irregular shape and sizes, and low bulk density, biomass is very difficult to handle, transport, store, and utilize in its original form. One solution to these problems is densification of biomass materials into pellets, briquettes, or cubes. Densification increases the bulk density of biomass from an initial bulk density (including baled density) of 40-200 kgm-3 to a final bulk density of $600-800 \mathrm{~kg} / \mathrm{m} 3$ (Mc Mullen, et al 2005). The burning of agricultural wastes causes' air pollution, soil erosion, and a decrease in biological activity, which eventually leads to lower yields. However, burning yields smoke and other pollutants which adversely affect air quality, visibility, and human and environmental health. The low sulphur content of crop residues as compared to fossil fuels and their use as fuel does not add to the $\mathrm{CO} 2$ content of the atmosphere (Dubey, et al 2007). Densification process to create strong and durable bonding in densified products such as pellets, briquettes, and cubes can be determined by quality testes which include testing the strength (compressive resistance, impact resistance and water resistance) and durability (abrasion resistance) of the densified products These tests can indicate the maximum force/stress that the densified products can withstand, and the amount of fines produced during handling, transportation and storage (Nalladurai and Morey 2009). The durability of briquettes is a measure of the ability of the briquettes to withstand the destructive forces such as compression, impact and shear during handling and transportation. In addition, the durability values represent the relative strength of the particle-particle bonding in the briquettes/pellets (Nalladurai and Morey 2010). Pellet biomass fuels are compressed, homogenized and dried biomass fuels that possess several advantages during handling, storage and combustion when compared to unprocessed biomass fuels. Environmentally, pellet biomass fuels provide advantages of less ash, smoke and other compound emissions, including carbon particles, $\mathrm{CO}, \mathrm{NOx}$ and SOx. Because the use of biomass pellets produces much fewer greenhouse gases when the biomass is sustainably harvested, there has been a recent push to replace fossil fuels with biomass fuels (Panwar, et al 2011).

Emissions characteristics from the combustion of five date palm residues, DPR, (Date Palm Leaflets, Date Palm Rachis, Date Palm Trunk, Date Stones and fruit stalk prunings) in a laboratory scale furnace were investigated. Release of gaseous products such as $\mathrm{CO} 2, \mathrm{CO}, \mathrm{VOC}, \mathrm{NOx}$ and $\mathrm{SO} 2$ were measured at $600-800{ }^{\circ} \mathrm{C}$. The main goal was to analyze thermal behaviors and gaseous emissions in order to select the most convenient biofuel for an application in domestic boiler installations. Regards to biofuel characteristics, date stone have the highest energy density $(11.4 \mathrm{GJ} / \mathrm{m} 3)$ and the lowest ash content (close to $1.2 \%$ ). Combustion tests show that among the tested date palm residues, date stone may be the promising biofuel for the design of combustion processing system. However, a special attention to the design of the secondary air supply should be given to prevent high emissions of CO and volatile matters (Yassine et al, 2013).

The objectives of the present study were to (i) to evaluate the physical characteristics of chopped date palm residues and (ii) to evaluate the shear, compression, bending test, the tensile, compressive strength according to various date palm stalk regions at different moisture contents and (iii) to establish the 
quality properties for briquettes were durability, compression ratio hardness, bulk density, compression ratio, resiliency, water resistance and gases emission.

\section{Materials and Methods}

\subsection{Materials}

\subsubsection{Chopper Machine}

The cutting machine, which used in this weork, is illustrated photographed in Figure 1 and schematically in Figure 3. it consists of the following parts; (1). The main frame; (2) Cutting-head: Cutting-head of a diameter $54 \mathrm{~cm}$ has two radial knives which are fixed on it by four bolts. It was rotate with speed of 1200, 1600 and $2000 \mathrm{rpm}$, respectively. (3) Feeding drum: Feeding drum dimension of $37 \mathrm{~cm}$ length, $14 \mathrm{~cm}$ diameter and $5.5 \mathrm{~cm}$ height was constructed in the machine. It considered an assistant element in the cutting process, which was used to push the plant stems to the cutter-head for cutting. (4) Power transmission: The power was transmitted to the cutter-head and feeding drum from powered by $30 \mathrm{~kW}$ Electric Motor. Two pulleys (driver and driven) transport the power to the cutter-head through and four "V" belts. (5) Feeding tray: Feeding tray with a dimension of $90 \mathrm{~cm}$ length, $60 \mathrm{~cm}$ outer width and $37 \mathrm{~cm}$ inner width was used in the machine. The side wall height was $20 \mathrm{~cm}$. (6) The source of power: Powered by $30 \mathrm{~kW}$ Electric Motor was used in this work to be a source of power for the chopping. (7) Knives: The cutting knives of spring steel were sharpened at angle $30^{\circ}$ to be used as a chopping member. The cutting knives were 25 $\mathrm{cm}$ length, $6 \mathrm{~cm}$ width and the thickness was $1.2 \mathrm{~cm}$.

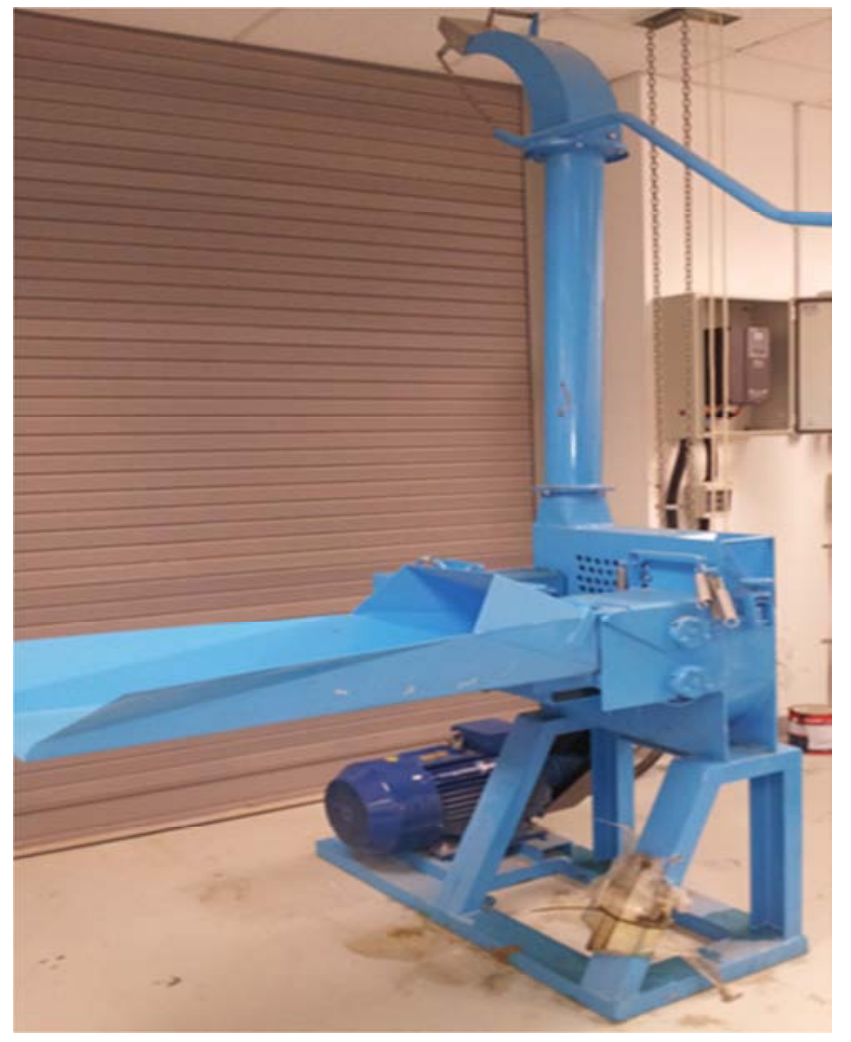

Figure 1. A photographic picture of the chopping machine.

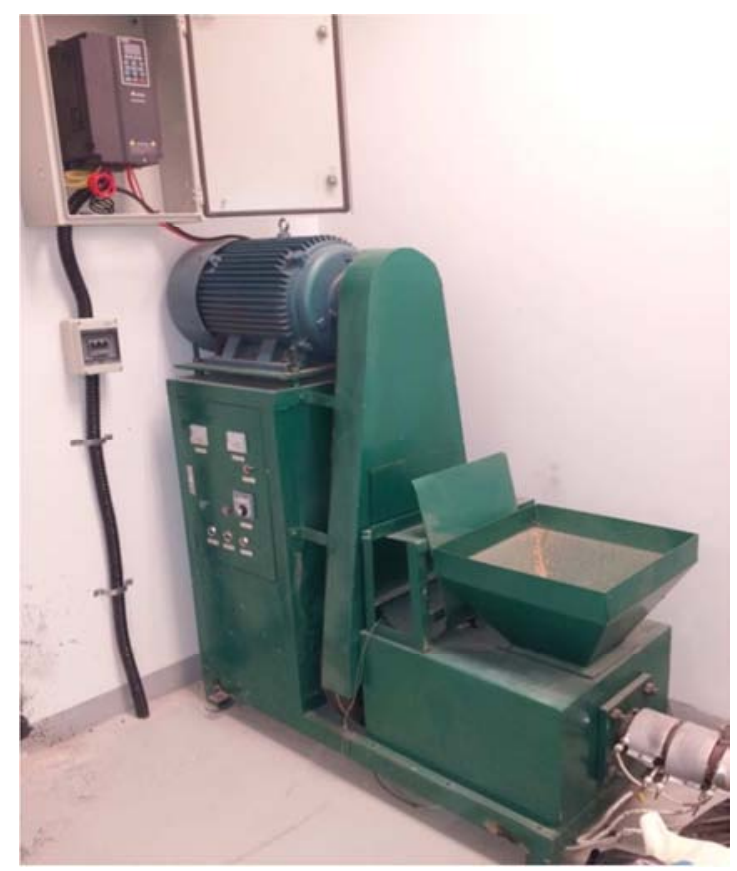

Figure 2. Briquetting press machine.

\subsubsection{Digital Force Gauge}

The advanced digital force gauge (M5-1000, USA) was used to measure the acting force (shear force, compression force at horizontal plane and maximum bending force) for date palm stalks. A small fixture was fabricated to hold samples to help for produce shear, compression and maximum bending force testes.

\subsubsection{Screw Press Machine}

The biomass briquette screw press equipped with automatic temperature control system are designed to produce high density wood briquette from biomass. (Type ZBJ-III). The production capacity of the machine was $230-280 \mathrm{~kg} / \mathrm{h}$. The press machine is powered by $18.5 \mathrm{~kW}$ electric motor. This machine can be operated 16 hours per day. It has 2 electrical ceramic heater bands each required $3 \mathrm{~kW}$ for operation and has an integrated "T" Stirrer with a $1.5 \mathrm{~kW}$ Motor. The press requires a standard 380 Volt, $50 \mathrm{~Hz}$ and 3 phase electrical driven motor. The machine has also a control panel. The chopped materials were put in a container above the machine. The materials feeding were rotated with different velocities with a belt. The operating velocity of the belt was $0.38 \mathrm{~m} / \mathrm{s}$. The screw press illustrated schematically in Figure 4 and photographed in Figure 2.

The main parts of the machine are screw and die; the rotating screw takes the material from the feet port and compacts it against the die which assists the build up of a pressure gradient along the screw. During this process, a frictional effect causes at the die wall. In addition, the combined effect due to the internal friction in the material and the high rotational speed of the screw cause an increase in temperature in the closed system which helps in heating the material. Then it forced through the die, where the briquette with the required shape is formed. 


\subsection{Experimental Procedure}

Date Palm residues with different moisture content were used at different moisture content. The electrical drying oven was used to dry the samples of residues to calculate the moisture content.

The chopped materials were pressed in a screw press machine at the Department of Agricultural Systems Engineering, King Faisal University, at (8, 10, and 12\%) and $(8,10$, and $12.8 \%)$ moisture content for date palm stalks (Fronds), date palm leaflets with and without binder, respectively.

The binder (urea-formaldehyde).

Urea-formaldehyde (thermal glue) Characterized by the following:

Color (Milky white), Focus ( 55 to $66 \%$ solids), Density (1.25 g / cm 3), Viscosity (from $200-1000 \mathrm{~cm} \mathrm{Boaz)} \mathrm{and} \mathrm{PH}$ (7-8). Percentage of free formaldehyde: not more than $1 \%$. Urea-formaldehyde is added by a rate $10 \%$ of the total weight of residues to be pressed.

\subsection{Measurements}

\subsubsection{Determination of Mechanical Properties}

The properties which influence the cutting process are the elastic behavior of the stem in shear, compression and bending Chattopadhyay \& Pandey, (1999) and Amer Eissa et al., (2008). Mechanical tests including force deformation and compressive strength for all residuals were measured as shown in Figure 5.

\section{i.Shear}

The indices which determine the shearing behavior of the plant material are maximum shear strength $\sigma$ s and specific cutting energy ESS. The maximum shear strength is expressed by:

$$
\sigma_{s}=\frac{F_{\max }}{A}
$$

where $\sigma$ s are the maximum shear strength in (MPa), Fmax is the maximum shear force in $(\mathrm{N})$ and $\mathrm{A}$ is the cross-sectional area of stalk at the plane of shear in $\left(\mathrm{mm}^{2}\right)$.

The specific cutting energy is found by determining the area under the shear force vs. displacement curve. In this case, it was found by

In this study, the compressive force vs. displacement curve consistently remained linear for a knife displacement of 10 $\mathrm{mm}$. Here, the compressive energy Ec was found by

$$
\mathrm{E}_{c}=\frac{1}{A} \int F_{c} d x=\frac{n \times f}{A}
$$

\section{ii. Bending}

The indices which determine the bending behavior of plant material are beam failure stress, modulus of elasticity in bending and bending energy. The beam failure stress $\sigma \mathrm{b}$ in (MPa) can be expressed by the following equation:

$$
\sigma_{b}=\frac{M y}{I} \text { and } M=F_{b} \times L
$$

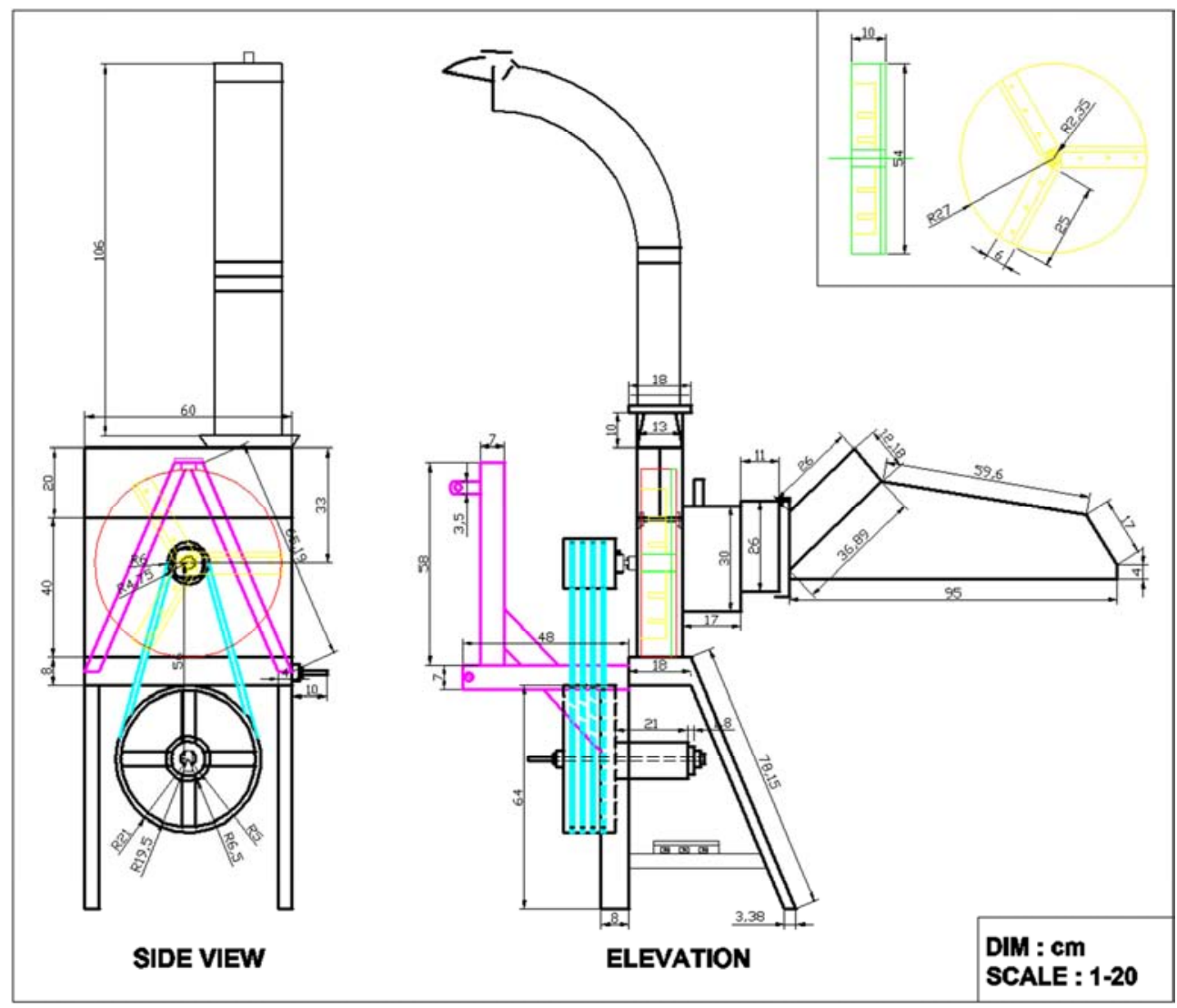

Figyre 3. Side view and elevation of the chopping machine. 


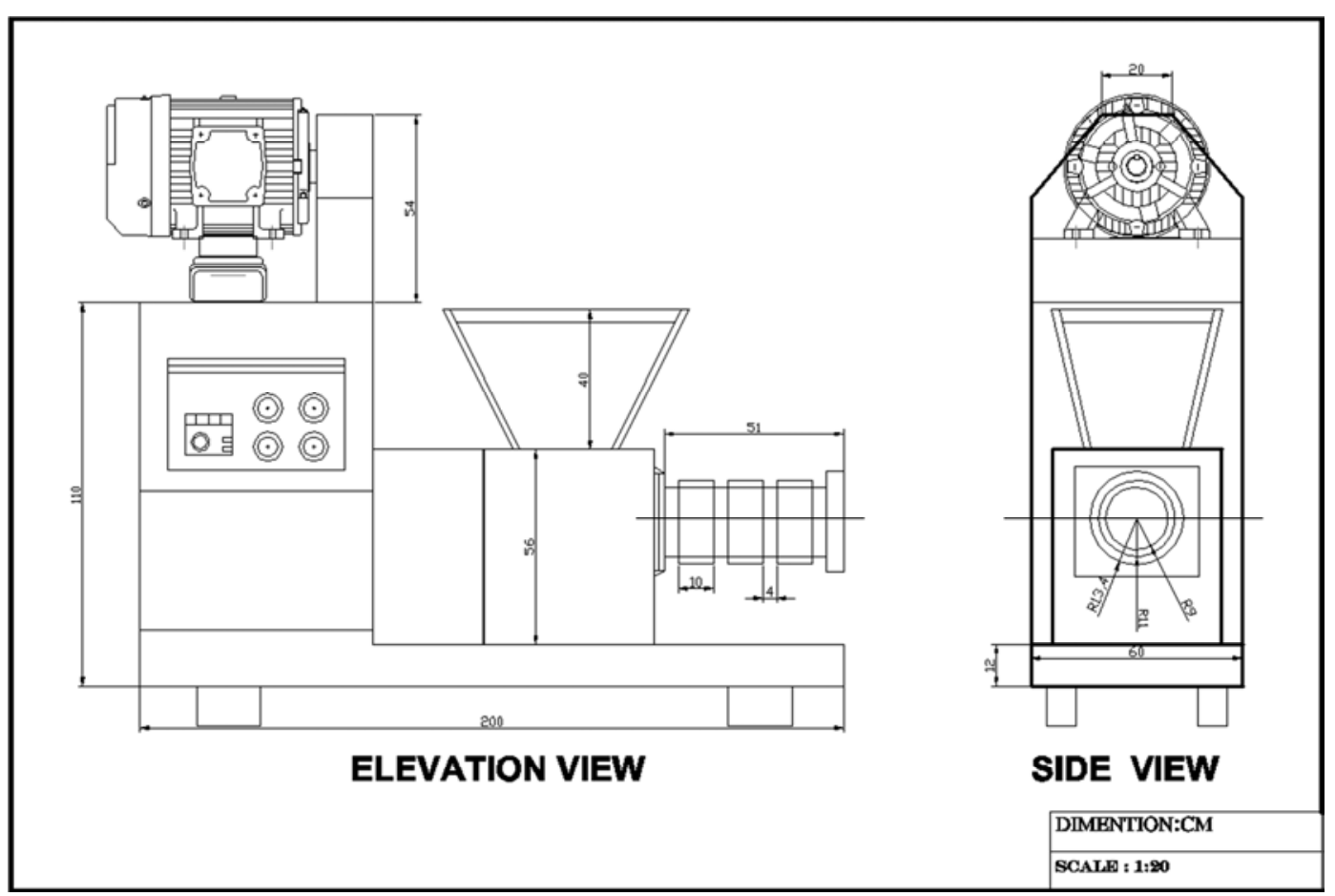

Figure 4. The Screw Press Machine.

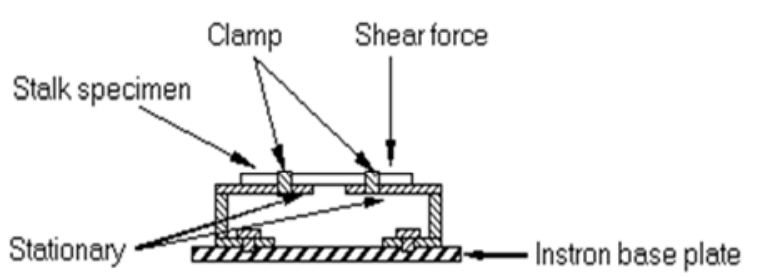

(a)

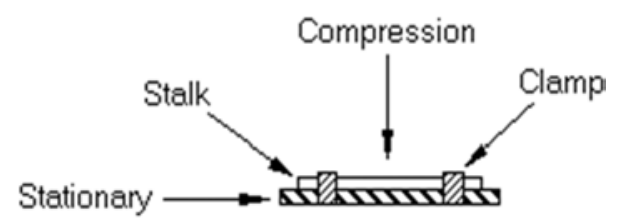

(b)

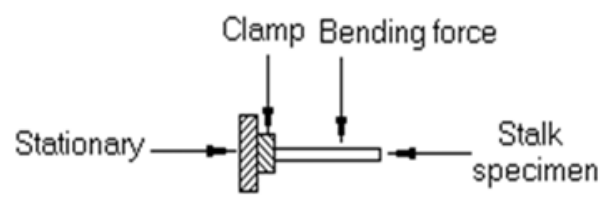

(c)

Figure 5. Schematic experimental arrangement for (a) shear, (b) compression and (c) bending test.

$$
\mathrm{E}_{S S}=\frac{1}{A} \int F d x=n \times \frac{f}{A}
$$

where ESS is the specific shearing energy in $(\mathrm{mJ} \mathrm{mm}-2), \mathrm{F}$ is the shearing force in $(\mathrm{mJ}), \mathrm{x}$ is the knife displacement, $\mathrm{n}$ is the number of units under force-displacement curve on the universal testing machine (UTM) chart, and (f) is the scale factor of unit area.

\section{iii. Compression}

The indices which determine the compression behavior of plant material are the modulus of elasticity in compression and the compressive energy. The linear portion of the force-displacement curve is used to determine the modulus of elasticity in compression, which is given by

$$
\sigma_{c}=\frac{F_{c} / A}{\Delta L / d}=\frac{F_{c} d}{A \Delta L}
$$

Where $\sigma c$ is the modulus of elasticity in compression in $(\mathrm{N} / \mathrm{mm} 2) . \mathrm{Fc}$ is the compressive force in $(\mathrm{N}), \Delta \mathrm{L}$ is the transverse deformation due to compressive force in $(\mathrm{mm})$, and $\mathrm{d}$ is the diameter of the stalk at the point of compression in $(\mathrm{mm})$. The compressive energy is found by determining the area under the linear portion of the compressive force vs. displacement curve.

where $\mathrm{M}$ is the maximum bending moment at which the stem fails in (Nmm), $y$ is the distance of outermost fibre from the neutral axis in ( $\mathrm{mm})$, I is the second moment of area of the stem cross-section in $\left(\mathrm{mm}^{4}\right), \mathrm{Fb}$ is the maximum bending force at which the stem fails in $(\mathrm{N})$, and $\mathrm{L}$ is the length of lever arm of the bending force in ( $\mathrm{mm})$.

The modulus of elasticity in bending for a cantilever type beam is given by

$$
\sigma_{m b}=\frac{F_{b} L^{3}}{3 D I}
$$

where $\sigma \mathrm{mb}$ is the modulus of elasticity in bending, and D is the deflection at the point of applied force. The bending energy $\mathrm{Eb}$ is found by determining the area under the bending force vs. displacement curve. Here, this was found by 


$$
E_{b}=\frac{1}{A} \int F_{b} d x=\frac{n f}{A}
$$

The mechanical properties were calculated by using Eqns (1) to (5) at different various regions stalks Chattopadhyay \& Pandey, (1999) and Amer Eissa et al., (2008).

\subsubsection{Quality Properties for Briquettes}

\section{i. Briquettes Durability}

The durability $(\mathrm{Du})$ of the briquettes was determined according to ASAE Standard S269.4, (2003). A 500 g sample of briquettes was tumbled at $50 \mathrm{rpm}$ for $10 \mathrm{~min}$, in a dust tight enclosure. A No. 5 US Sieve with an aperture size of $4.0 \mathrm{~mm}$ was used to retain crumbled briquettes after tumbling. Durability is expressed by the percent ratio of mass of briquettes retained on the sieve after tumbling (mpa) to mass of briquettes tumbling (mpb) according to with the following equation (8). (Fasina 2008).

$$
D_{u}=\frac{m p a}{m p b} \times 100
$$

\section{ii. Compression Test}

The compression stress for each briquette was measured using a universal testing machine were performed by means of a TA-TX2 Texture Analyzer (Texture Technologies Corp., NY, USA). The flat surface of the briquette sample was placed on the horizontal metal plate of the machine. A motorized screw slowly reduced the distance between this metal plate and a second one parallel to it. An increased load was applied at a constant rate until the test sample failed by cracking or breaking. The load at the fracture point and the maximum load were converted to compression stress using the following equation (9). (Gibiiz, et al 1996).

$$
\text { Compression stress }=\frac{\text { Load at fracture }}{\text { Cross sectional area of plane of fracture }}
$$

\section{iii. Gases Emissions}

The emission was measured using analyzer (Testo 435) as shown in Figure 6. Estimated emissions were carbon monoxide (CO), carbon dioxide $\left(\mathrm{CO}_{2}\right)$, oxides of nitrogen (NOX), and sulfur dioxide $\left(\mathrm{SO}_{2}\right)$ for each date palm stalks (Fronds), date palm leaflets (loose and briquettes) samples at moisture content (7.4, 8.57 and $10.35 \%)$ and $(7.13,9.21$ and $10.98 \%)$ for date palm stalks (Fronds), date palm leaflets, respectively. The samples were burned in the stove and took the data of emissions from the chimney height of $180 \mathrm{~cm}$. Ethyl Alcohol was used as an assistant at the start of the burning process and the readings taken during the samples ignition. Combustion efficiency $(\eta)$ was calculated from the following equation (10):

$$
\eta \mathrm{e}=\mathrm{CO}_{2} \% /\left(\mathrm{CO} \% * \mathrm{CO}_{2} \%\right)
$$

\subsection{Methods}

The experiments were carried out in resistance of Laboratory to measured some quality properties for date palm stalks (Fronds), date palm leaflets briquettes such as the durability, compression stress, hardness, bulk density, compression ratio, resiliency, water resistance and gases emission.

\section{- Quality of Briquettes}

\section{i. Bulk Density $(\rho b)$}

Bulk density is an indicator of savings in storage, transportation space and cost of blocks. The bulk density of the briquettes was calculated by Eq. (11), (Jha et al 2008).

$$
\rho_{b}=\frac{W}{L \times B \times T}
$$

$\rho \mathrm{b}=$ bulk density of date palm stalks briquette, $\mathrm{kgm}^{3}$

$\mathrm{W}=$ weight of date palm stalks briquette, $\mathrm{kg}$

$\mathrm{B}=$ width of date palm stalks briquette, $\mathrm{mm}$

$\mathrm{L}=$ length of date palm stalks briquette, $\mathrm{mm}$

$\mathrm{T}=$ thickness of date palm stalks briquette, $\mathrm{mm}$
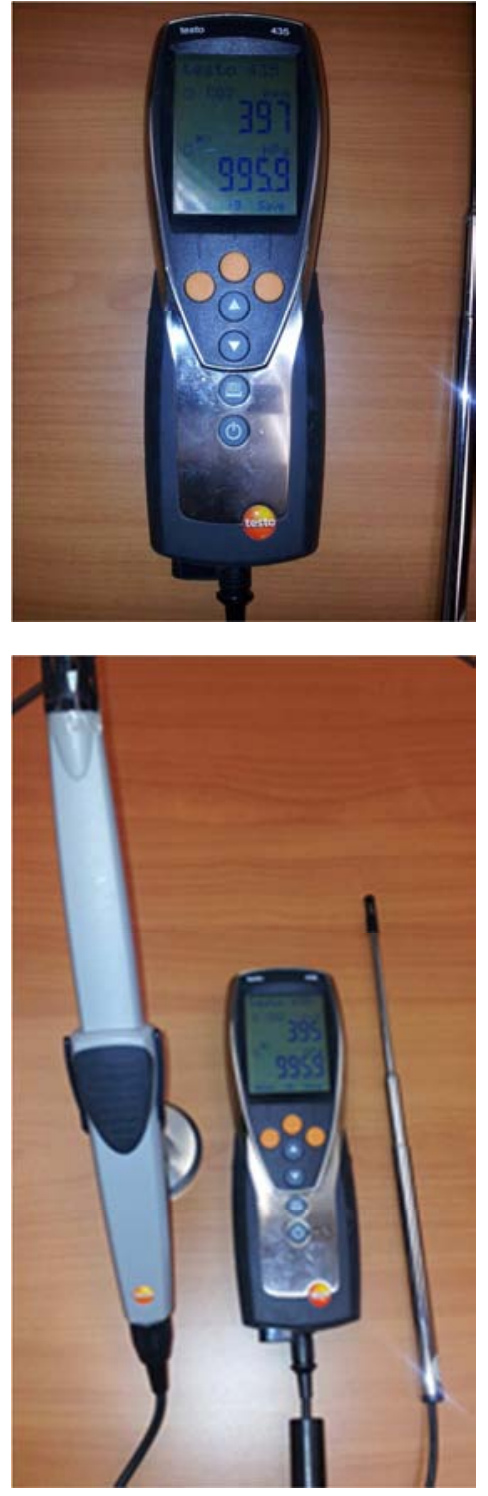

Figure 6. The measuring emissions device (Testo). 


\section{ii. Compression Ratio (CR)}

The compression ratio indicates volume reduction during compression. It was obtained from the ratio of bulk density of compact block to the initial density of the material being compressed. According to Eq. (12). (Jha et al 2008)

$$
\mathrm{CR}=\frac{\rho_{\mathrm{b}}}{\rho_{\mathrm{raw}}}
$$

$\mathrm{CR}=$ compression ratio

$\rho b=$ bulk density of date palm stalks briquettes, $\mathrm{kgm}^{3}$ praw $=$ bulk density of loose date palm stalks, $\mathrm{kgm}^{3}$ iii. Resiliency $(R)$

Resiliency was determined as the ratio of the increase in thickness to the initial thickness of the briquette according to Eq. (13). (Jha et al., 2008)

$$
R=\frac{T-T_{i}}{T_{i}}
$$

$\mathrm{R}=$ resiliency, $\%$

$\mathrm{T}=$ thickness of stabilised date palm stalks briquette, $\mathrm{mm}$

$\mathrm{T}_{\mathrm{i}}=$ initial thickness of date palm stalks briquette, $\mathrm{mm}$

iv. Hardness

Hardness reflects the degree of binding. It was measured as the maximum force recorded while a briquette was broken by a probe incorporated in a Texture Analyser (Jha et al 2008).

v. Water Resistance

The water resistance of the briquettes was tested by immersing them in a glass container filled with cold tap water and measuring the time required for onset of the dispersion in water (Yamnan, et al 2001 and Debdoubi, et al., 2005).

\section{Results and Discussion}

\subsection{Mechanical Properties of Palm Fronds}

The mechanical properties which studied for date palm stalks were shear stress, compressive stress and bending moment. The mechanical properties may be defined as those properties that determine the behavior of material under applied loads.

\subsubsection{Shear Stress}

Shear stress of Palm fronds at the three level of moisture content $(12.63,33.21$, and 60.54\%) presented in Figure 7 and Table 1. It is clear that, increasing shear stress values from the bottom stem is than the top of Palm fronds. The greatest value of shear stress obtained at the bottom. This due to its more fiber and a thicker stem wall than at the top part. The shears stress increasing from 4.44 to $7.83 \mathrm{MPa}$ with decreasing moisture content from $60.54 \%$ to $12.63 \%$ at the bottom part. The shear stress was $(5.13,6.24,7.83 \mathrm{MPa})$ at bottom, middle, upper part of the fronds at $12.63 \%$ moisture content, respectively.

\subsubsection{Compression Stress}

Table 1 showed compression stress of Palm fronds at different moisture contents $(12.63,33.21$, and $60.54 \%)$ is presented in Figure 8 , it is showed clear that, increasing compression stress at the bottom stem more than top stem part of Palm fronds. The maximum compression stress was found at the bottom part of Palm fronds. This may be due to its more fiber and a thicker stem wall than at the top part. The maximum compression stress was greatest for the fronds at the bottom. The compressive stress was $(3,3.62,4.78 \mathrm{MPa})$ at bottom, middle and top part of the stalk at $12.63 \%$ moisture content, respectively.

\begin{tabular}{|c|c|c|c|c|c|}
\hline \multirow{2}{*}{ Position } & \multicolumn{2}{|l|}{ Dimensions } & \multirow{2}{*}{$\begin{array}{l}\text { Shear stress } \\
\text { (MPa) }\end{array}$} & \multirow{2}{*}{ Compressive stress (MPa) } & \multirow{2}{*}{ Binding moment (N.m) } \\
\hline & Width (mm) & Thickness (mm) & & & \\
\hline \multicolumn{6}{|c|}{ Moisture Content (M. C., 12.63\%) } \\
\hline Bottom & 15.25 & 11.1 & 7.83 & 4.78 & 27.6 \\
\hline Middle & 12.5 & 10 & 6.24 & 3.62 & 13.82 \\
\hline Top & 8.25 & 7.25 & 5.13 & 3 & 9.56 \\
\hline \multicolumn{6}{|c|}{ Moisture Content (M. C., 33.21\%) } \\
\hline Bottom & 14 & 12.5 & 5.69 & 4 & 22.2 \\
\hline Top & 6.75 & 5.75 & 3.37 & 2.37 & 8.76 \\
\hline \multicolumn{6}{|c|}{ Moisture Content (M. C., 60.54\%) } \\
\hline Bottom & 13.25 & 10.75 & 4.44 & 3.64 & 17.78 \\
\hline Middle & 10.75 & 8.75 & 3.45 & 3.1 & 10 \\
\hline Top & 8.5 & 7.29 & 1.73 & 1.83 & 5.2 \\
\hline
\end{tabular}

Table 1. Shear stress, Compressive stress and Binding moment Test for palm frond stalks at different moisture content.

\subsubsection{Bending Moment}

Figure 9 and Table 1 showed that, the bending moment increased with decreasing moisture content of Palm fronds. The bending moment increasing from 17.78 to 27.6 N.m with decreasing moisture content from $60.54 \%$ to $12.63 \%$ at the bottom part. The maximum bending moment was greatest for the fronds at the bottom. The bending moment was $(9.56,13.82$, 27.6 N.m) at bottom, middle and top part of the stalk at $12.63 \%$ moisture content, respectively. Because the determined force to do bending and fracture for fronds increase at bottom more than at the middle and top part result of the accumulation of lignin, which increases hardening by decrease moisture content. Useful conclusions may be the analysis of the stalk phenomenon refers to the correlation of the main mechanical properties of these residues. Both the shear, compressive strength and bending moment were found to be higher in the lower region of the stalk due to structural heterogeneity.

\subsection{Evaluation of Local Chopping Machine with Palm Fronds}

Palm fronds used to evaluate the chopping machine in this study at different moisture content (12.63, 33.21 and $60.54 \%)$ 


\section{- Power Requirements}

\section{i. Total Power Requirements}

Figure 10 showed that, the total power requirements increased with increasing cutting drum speed. This may be due to increasing in amount of material to be cut by increasing cutting drum speed. The total power requirements increased from 7.56 to $9.10 \mathrm{~kW}$ with increasing cutting speed from 1200 $\mathrm{rpm}$ to $2000 \mathrm{rpm}$ at $12.63 \%$ moisture content. The total power requirements increased with increasing moisture content. The total power requirements increasing from 9.1 to $17 \mathrm{~kW}$ with increasing moisture content from $12.63 \%$ to $60.54 \%$ at 2000 rpm cutting speed.

The minimum value of total power requirement was 7.56 $\mathrm{kW}$ at $1200 \mathrm{rpm}$ cutting speed, and $12.63 \%$ moisture content while, the maximum value of total power requirement was 17 $\mathrm{kW}$ at $2000 \mathrm{rpm}$ cutting speed and $60.54 \%$ moisture content. Over all, the total power requirement increased with increase of moisture content and increase of cutting speed. Generally, the total power requirement depends on the cutting drum speed and the moisture content for palm fronds. That is may be due to the natural effect of speed on power and to accelerate the cut materials by increasing the cutting drum speed, the cut materials pass fast and longest through holes, without need for more power for cutting.

\section{ii. Net Power Requirements}

Figure 11 showed that, the net power requirements increased with increasing cutting drum speed. This may be due to increasing in the amount of material to be cut by increasing cutting drum speed. The net power requirements increased from 6 to $7.68 \mathrm{~kW}$ with increasing cutting speed from $1200 \mathrm{rpm}$ to $2000 \mathrm{rpm}$ at $12.63 \%$ moisture content.

The net power requirements increased with increasing moisture content. The net power requirements increased from 7.68 to $15.87 \mathrm{~kW}$ with increasing moisture content from $12.63 \%$ to $60.54 \%$ at $2000 \mathrm{rpm}$ cutting speed. The minimum value of net power requirement was $6.00 \mathrm{~kW}$ at $1200 \mathrm{rpm}$ cutting speed and $12.63 \%$ moisture content while, the maximum value of net power requirement was $15.87 \mathrm{~kW}$ at $2000 \mathrm{rpm}$ cutting speed and $60.54 \%$ moisture content. Over all, the net power requirement increased with increase of moisture content and cutting speed. The cutting power requirements were affected by cutting drum speed and the moisture content for palm fronds.

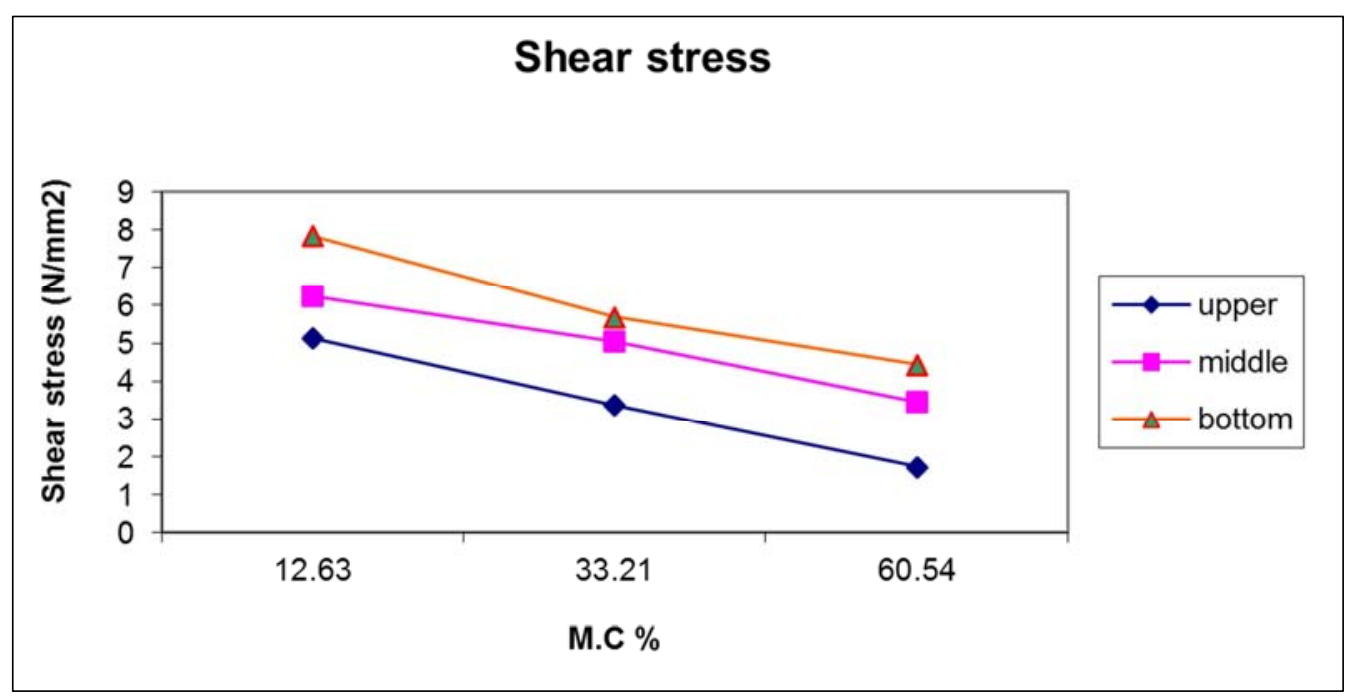

Figyre 7. The relationship between shear stress and moisture content for palm fronds at different positions of fronds (bottom, middle and top).

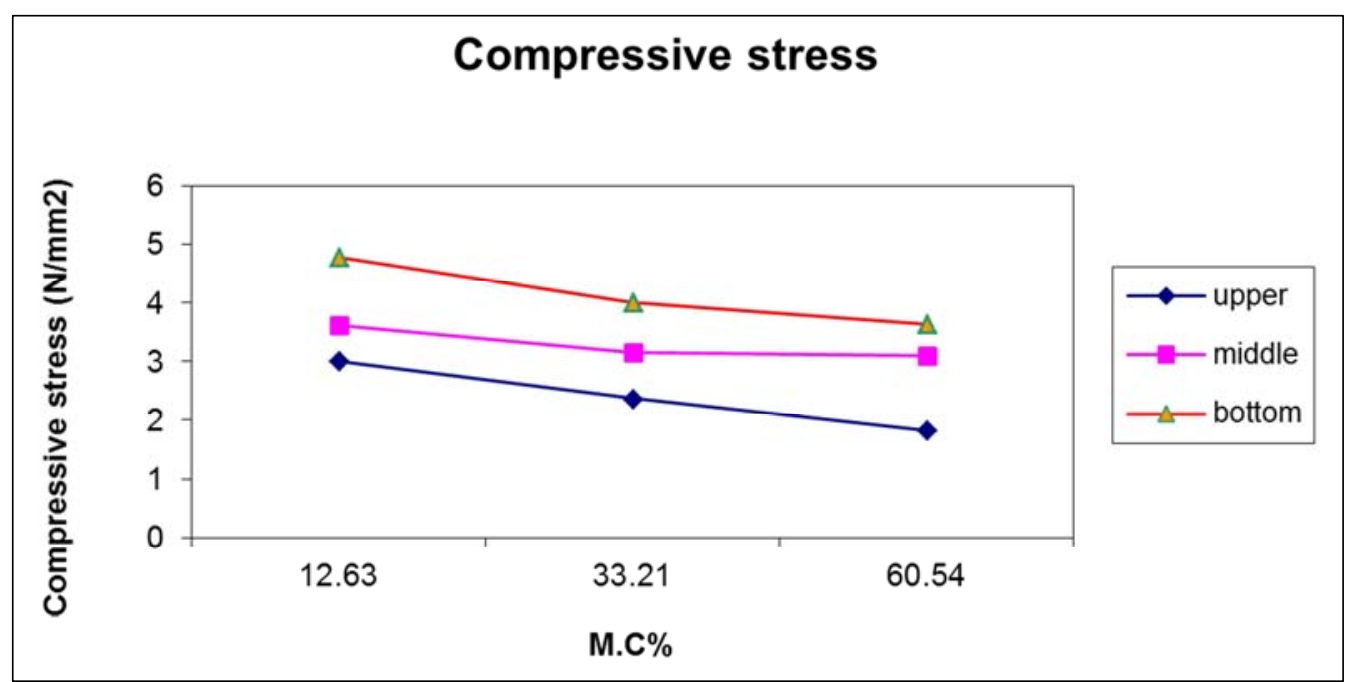

Figure 8. The relationship between compressive stress and moisture content for palm fronds at different positions of fronds (bottom, middle and top). 


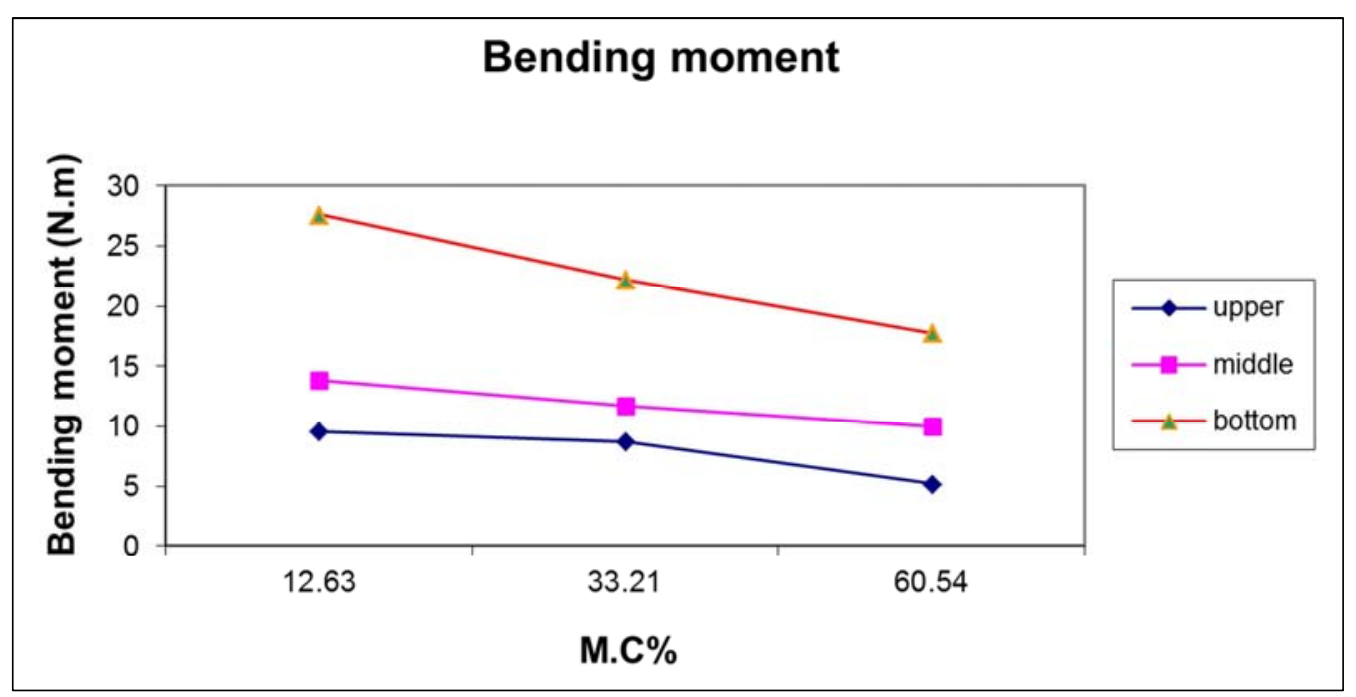

Figure 9. The relationship between bending moment and moisture content for palm fronds at different positions of fronds (bottom, middle and top).

\section{iii. Machine Productivity}

Figure 12 showed that, the machine productivity increased with increasing the cutting drum speed. The machine productivity was $0.69,0.7$ and 0.75 ton/h with increasing cutting speed from 1200, 1600 and $2000 \mathrm{rpm}$, respectively, at $12.53 \%$ moisture content. The minimum value of machine productivity was $0.52 \mathrm{ton} / \mathrm{h}$ at $1200 \mathrm{rpm}$ cutting speed and $60.87 \%$ moisture content while, the maximum value of machine production was $0.75 \mathrm{ton} / \mathrm{h}$ at $2000 \mathrm{rpm}$ cutting and $12.53 \%$ moisture content. The machine productions were affected by cutting drum speed. That is may be due to accelerate the cut materials by increasing the cutting drum speed, the cut materials pass easy through holes.

\section{iv. Energy Consumption}

Figure (13) showed that, the energy consumption decreased with increasing the cutting speed. The energy consumption was $17.66,14.53$, and $12.68 \mathrm{~kW} . \mathrm{h} / \mathrm{t}$ with increasing cutting drum speed from 1200, 1600 and $2000 \mathrm{rpm}$, respectively, at $12.53 \%$ moisture content. The minimum value of energy consumption was $12.68 \mathrm{~kW} . \mathrm{h} / \mathrm{t}$ at $2000 \mathrm{rpm}$ cutting speed and
$12.53 \%$ moisture content while, the maximum value of energy consumption was $12.68 \mathrm{KW} . \mathrm{h} / \mathrm{t}$ at $1200 \mathrm{rpm}$ cutting speed and $60.56 \%$ moisture content. That is may be due to increasing the machine productivity by increasing the cutting drum speed, the machine productivity increased.

\section{v. Cutting Efficiency}

Figure 14 showed that, the cutting efficiency increased with increasing cutting drum speed and decreasing moisture content. The cutting efficiency increased with increasing cutting drum speed, that is due to an increase in the number of cuts per time unite and this increase the weight of the suitable cutting length. The cutting efficiency increased from $74 \%$ to $93.73 \%$ with increasing cutting speed from $1200 \mathrm{rpm}$ to 2000 $\mathrm{rpm}$ at $12.63 \%$ moisture content. The results showed also that, increasing the cutting drum speed from 1200 to $2000 \mathrm{rpm}$ cutting efficiency increased from $(74,71.55$ and $61.45 \%)$ to $(93.73,91.48$ and $85.76 \%$ ) at $12.63,33.21$ and $60.54 \%$ moisture content, respectively. That is may be due to decreasing the cut lengths of date palm stalks by increasing the cutting drum speed.

Table 2. The relation between cutting drum speed and Cutting efficiency\% at different levels of moisture content for palm fronds.

\begin{tabular}{lllllll}
\hline M. C\% & $\begin{array}{l}\text { Cutting speed } \\
\text { (r.p.m) }\end{array}$ & $\begin{array}{l}\text { Total power } \\
\text { required, (kW) }\end{array}$ & Net power required (kw) & $\begin{array}{l}\text { Machine Production } \\
\text { (t/h) }\end{array}$ & $\begin{array}{l}\text { Energy Consumption, } \\
\text { kW.h/t }\end{array}$ & Cutting Efficiency\% \\
\hline \multirow{3}{*}{12.63} & 1200 & 7.56 & 6 & 0.69 & 17.66 & 74 \\
& 1600 & 8.92 & 7.4 & 0.7 & 14.53 & 86.54 \\
& 2000 & 9.1 & 7.68 & 0.75 & 12.68 & 93.73 \\
33.21 & 1200 & 9.2 & 8.7 & 0.64 & 18.43 & 71.55 \\
& 1600 & 10.48 & 9.32 & 0.66 & 16.28 & 83.44 \\
60.54 & 11.600 & 11.65 & 10.43 & 0.675 & 13.78 & 91.48 \\
& 1200 & 11.2 & 11.45 & 0.52 & 24.34 & 61.45 \\
& 1600 & 15 & 13.56 & 0.54 & 19.27 & 74.83 \\
\end{tabular}




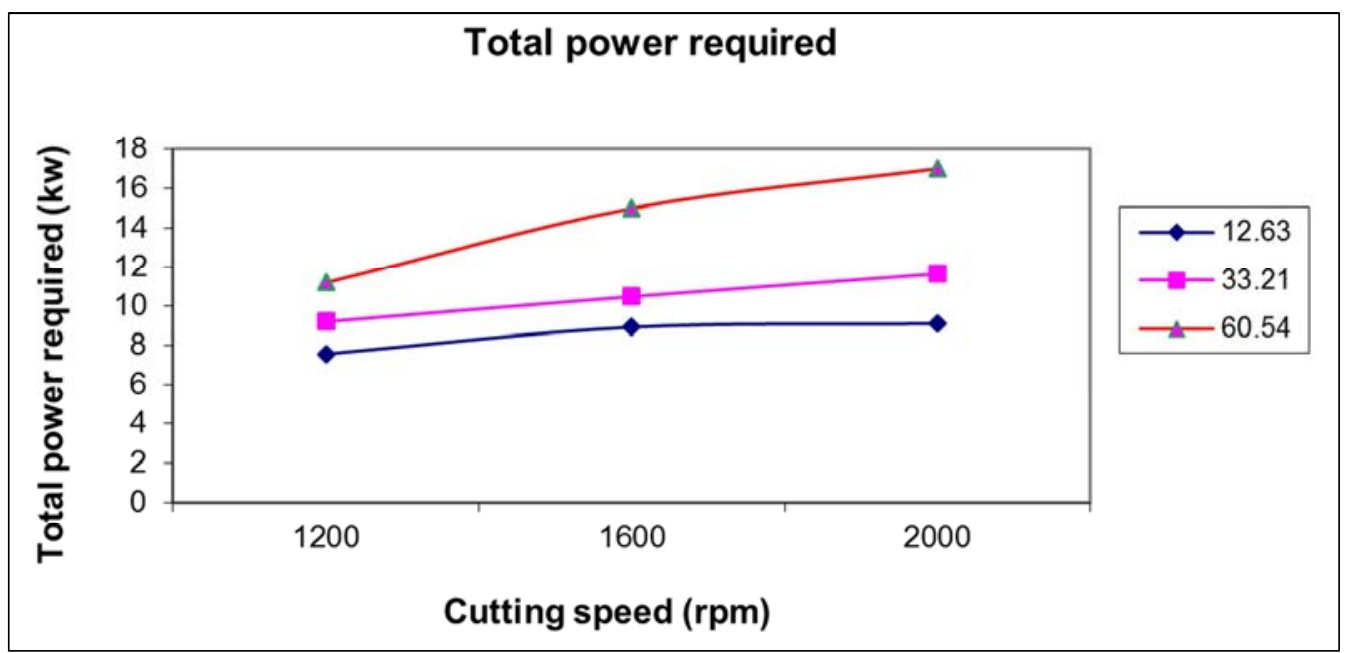

Figure 10. The relationship between cutting drum speed and total power requirement at different levels of moisture content (12.63\%, 33.21\% and 60.54\%) for Palm fronds.

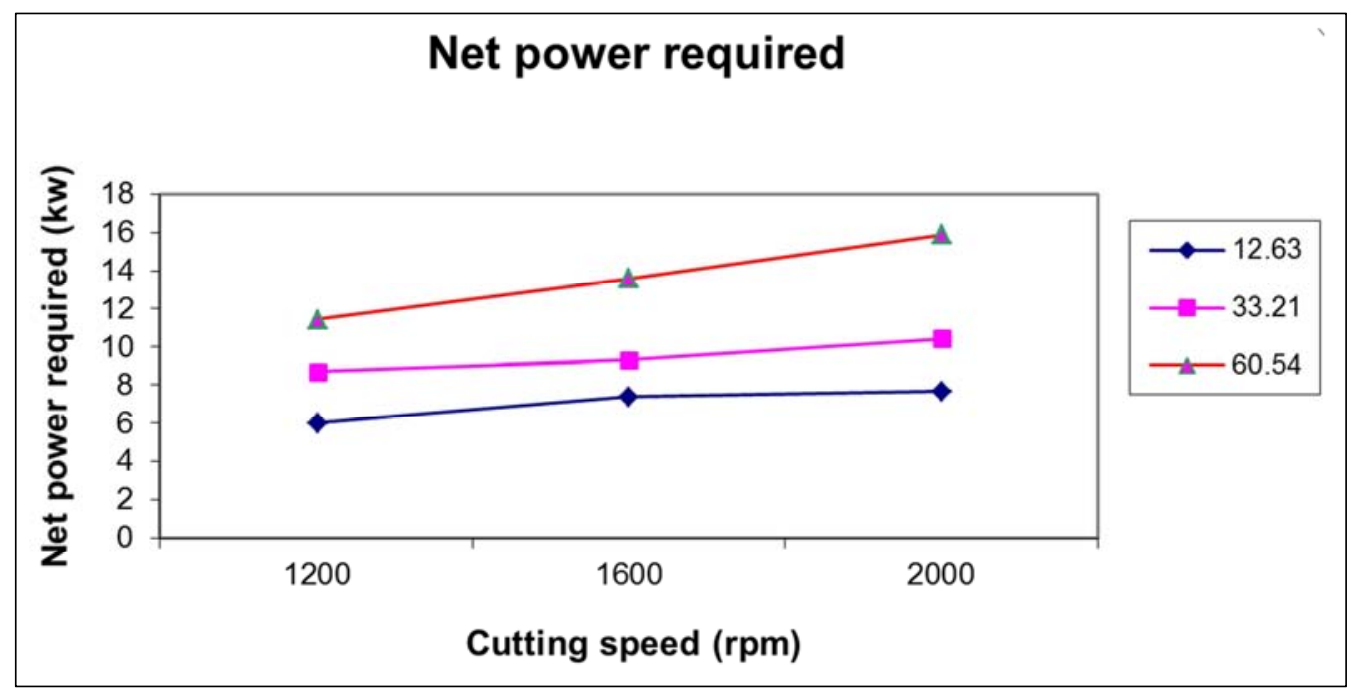

Figure 11. The relationship between cutting drum speed and net power requirement at different levels of moisture content for Palm fronds.

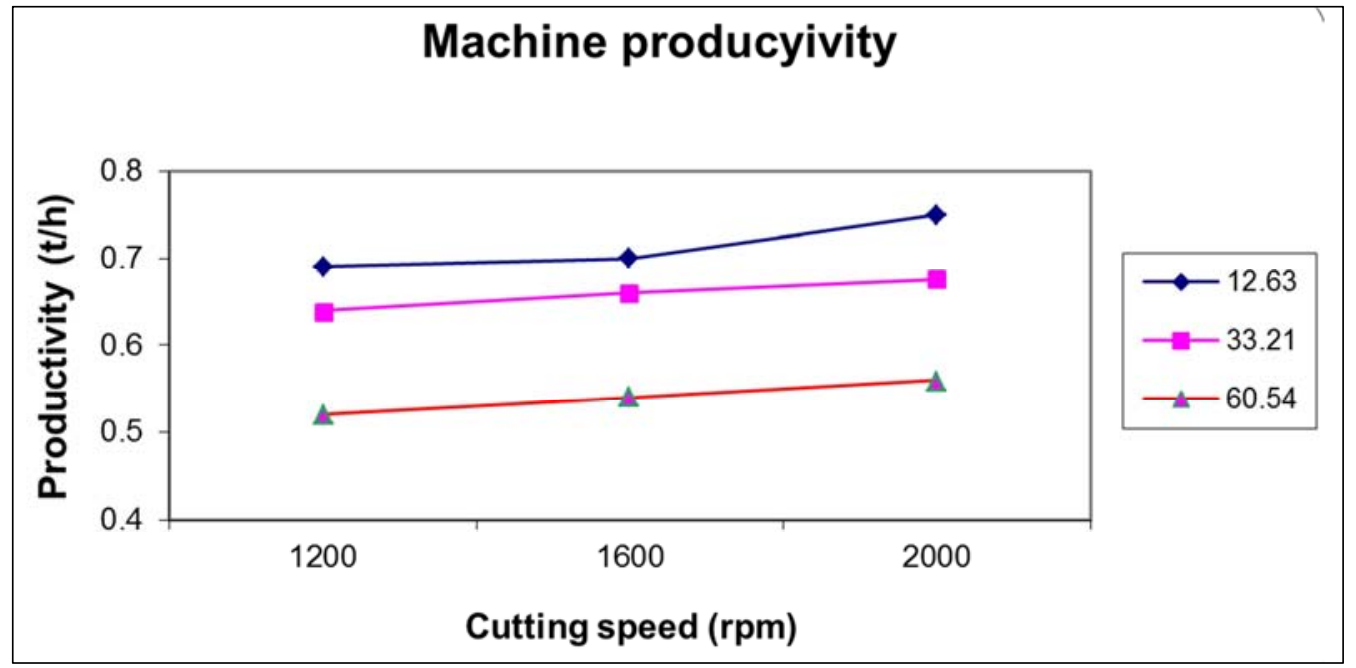

Figure 12. The relationship between cutting drum speed and machine production at different levels of moisture content for Palm fronds. 


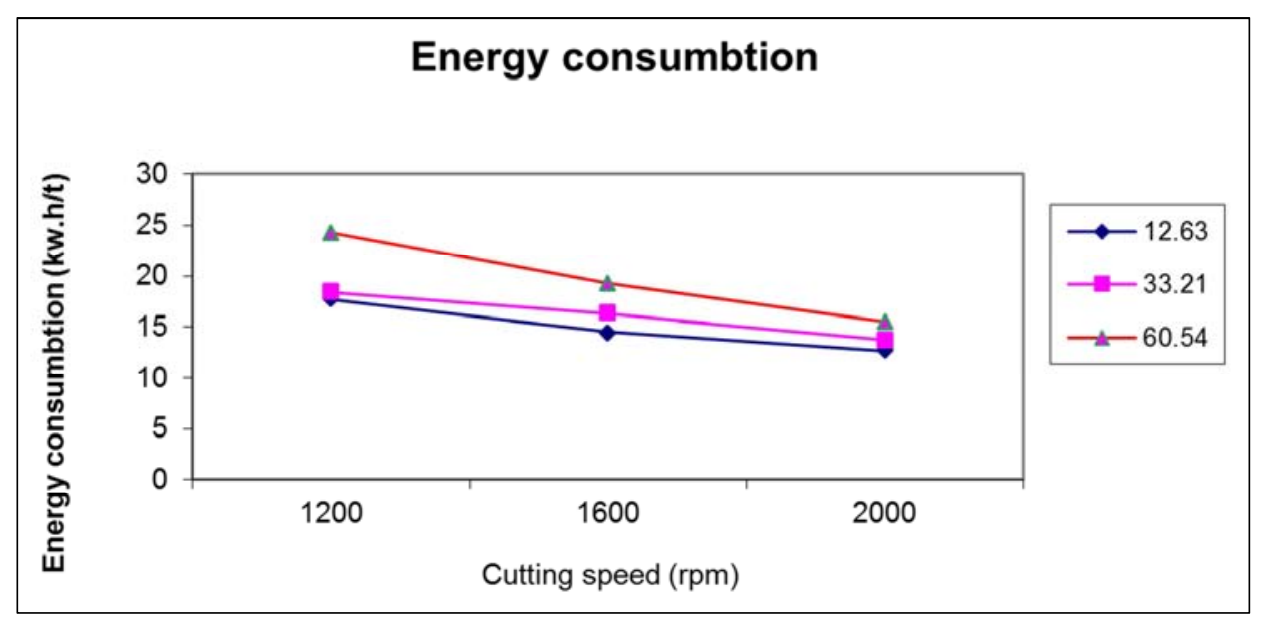

Figure 13. The relationship between cutting drum speed and energy consumption at different levels of moisture content for Palm fronds.

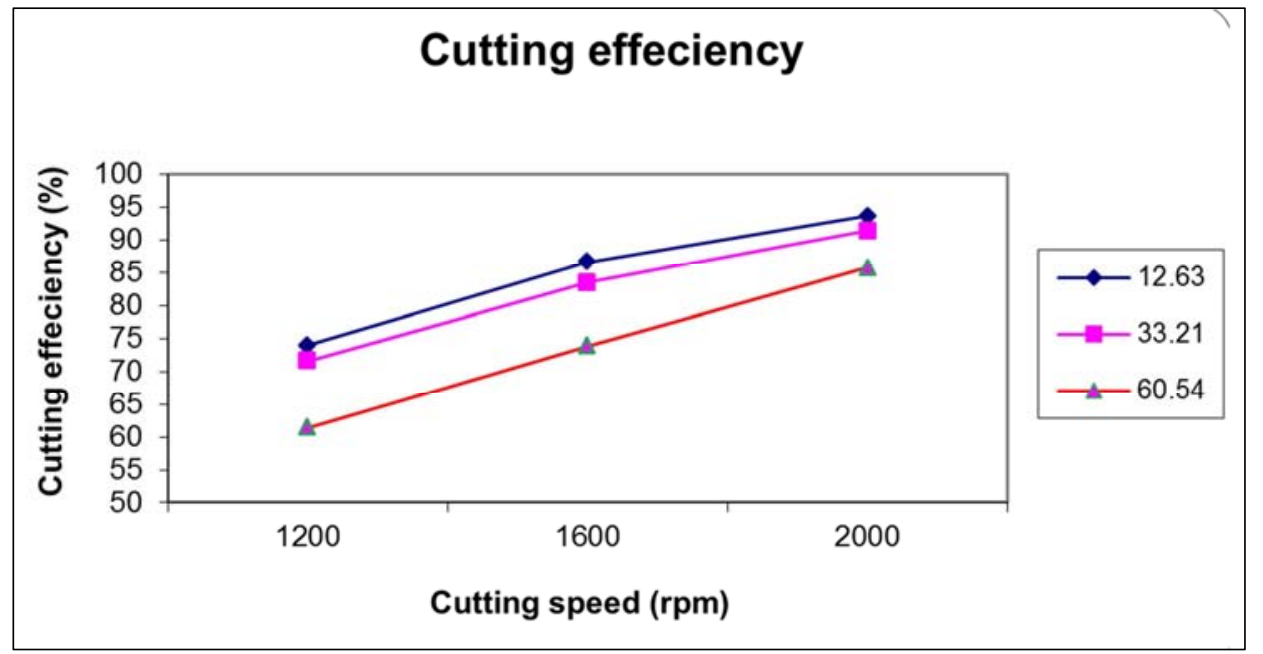

Figure 14. The relationship between cutting drum speed and cutting efficiency at different levels of moisture content for Palm fronds.

\subsection{Moisture Content for Date Palm Stalks (Fronds), Date Palm Leaflets Briquettes}

Figure 15 shows that, after the pressing of the chopped date palm stalks (Fronds), date palm leaflets to briquettes, the moisture content decreased compared with before the pressing. Moisture content of date palm stalks (Fronds) briquettes were pressed at 8 ,
10 and $12 \%$ decreased to $7.4,8.57$ and $10.35 \%$, respectively. While moisture content of date palm leaflets briquettes were pressed at 8,10 and $12.8 \%$ decreased to $7.13,9.21$ and $10.98 \%$, respectively. The decrement percentages of moisture content were (7.5, 7.9 and $13.75 \%)$ and (10.87, 12.5 and 8.5\%) for date palm stalks, date palm leaflets briquettes, respectively.

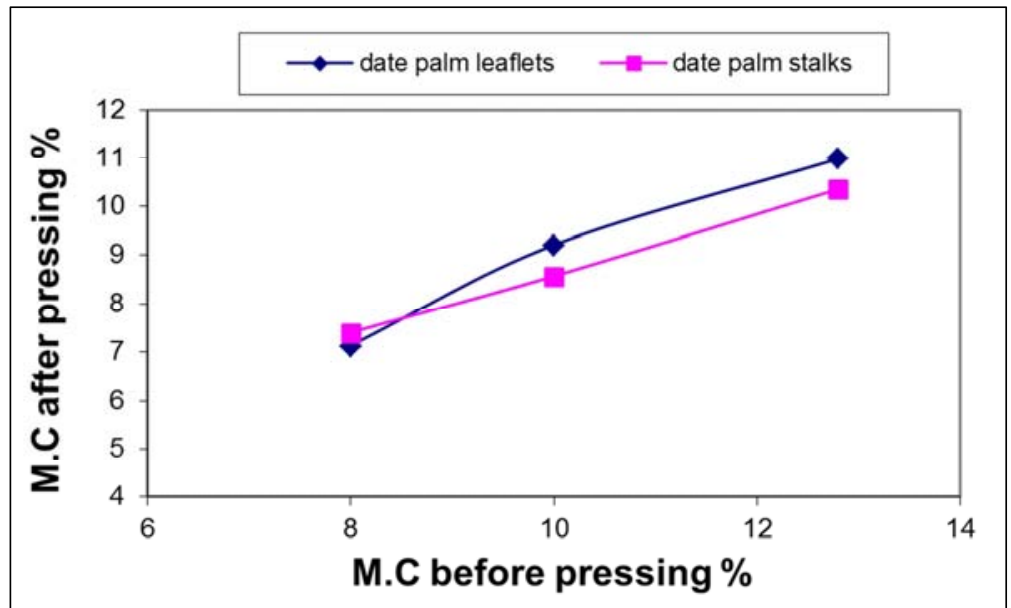

Figure 15. The effect of pressing on the moisture content of date palm stalks (Fronds), date palm leaflets briquettes. 


\subsection{Effect of Moisture Content on Compression Stress and Durability for Date Palm Stalks (Fronds), Date Palm Leaflets Briquettes}

The relation between compression stress and durability with moisture content for date palm stalks (Fronds), date palm leaflets briquettes are shown in Figure 16a and 16b. It can be noticed that, increase of moisture content decreased the compression stress and durability. And show that, the values of the moisture content and compression stress for briquettes presented as contour (line dark) red on the horizontal plane. It shows the highest values for the durability $(>90 \%),(>80 \%)$ and (>94\%), (>94\%) for date palm stalks (Fronds), date palm leaflets briquettes, without binder and with binder, respectively.

Compression stress \%

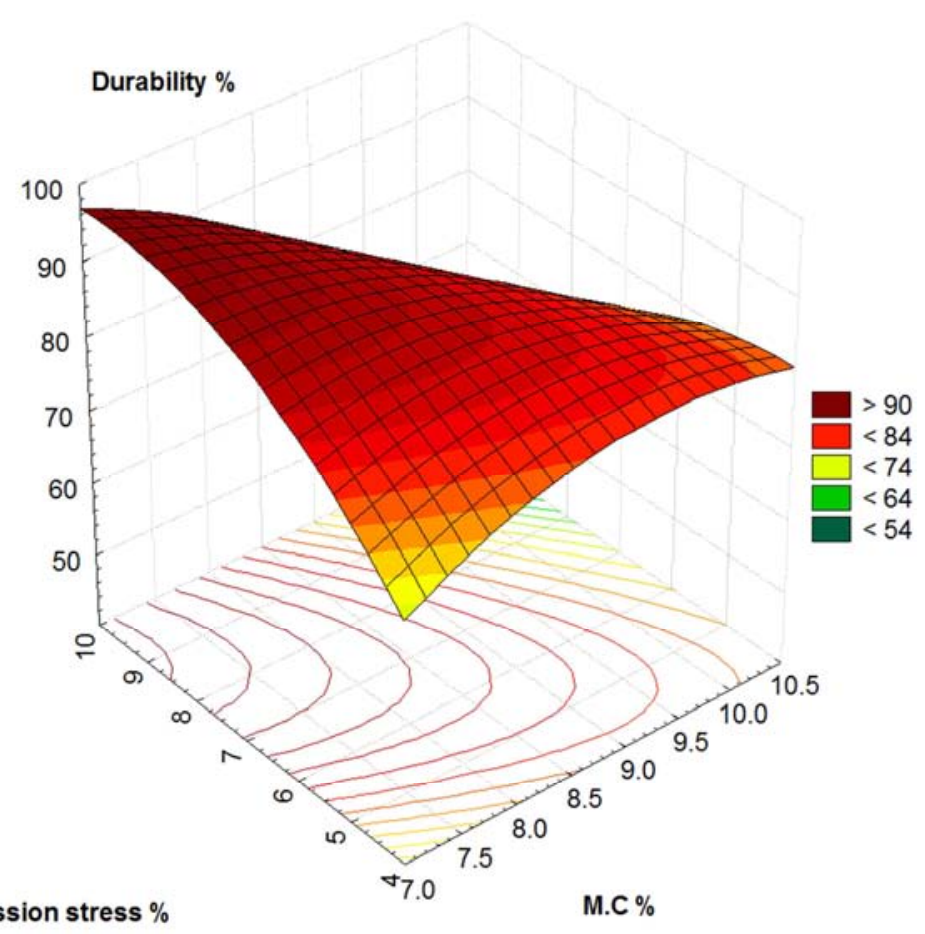

Without binder

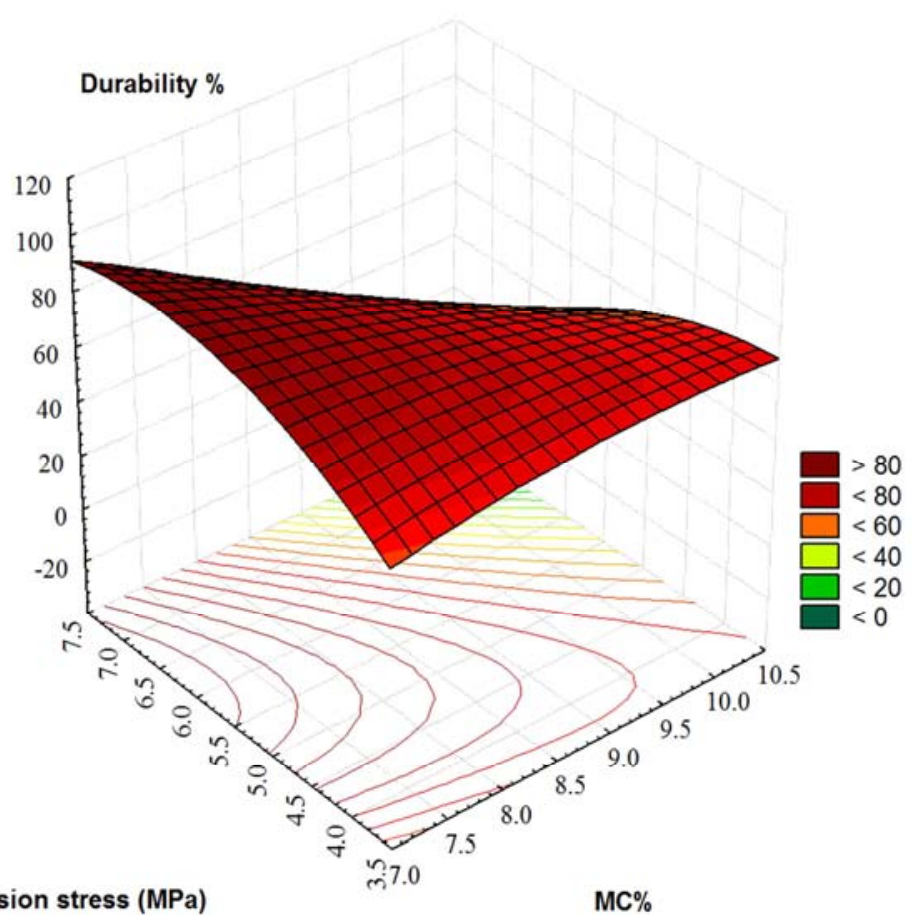

Compression stress (MPa)

$\mathrm{MC} \%$

With binder

Figure 16a. Effect of moisture content on compression stress and durability for date palm stalks (Fronds) briquettes. 


\subsection{Effect of Moisture Content on Compression Stress and Resiliency for Date Palm Stalks (Fronds), Date Palm Leaflets Briquettes}

The relation between compression stress and resiliency with moisture content for date palm stalks (Fronds), date palm leaflets briquettes are shown in Figure 17a and 17b. It can be noticed that, increase of moisture content decreased the compression stress and resiliency increased. And show that, the values of the moisture content and compression stress for briquettes presented as contour (line dark) red on the horizontal plane. It shows the highest values for the resiliency $(>10),(>12)$ and $(>19),(>14)$ for date palm stalks (Fronds), date palm leaflets briquettes without binder and with binder, respectively.
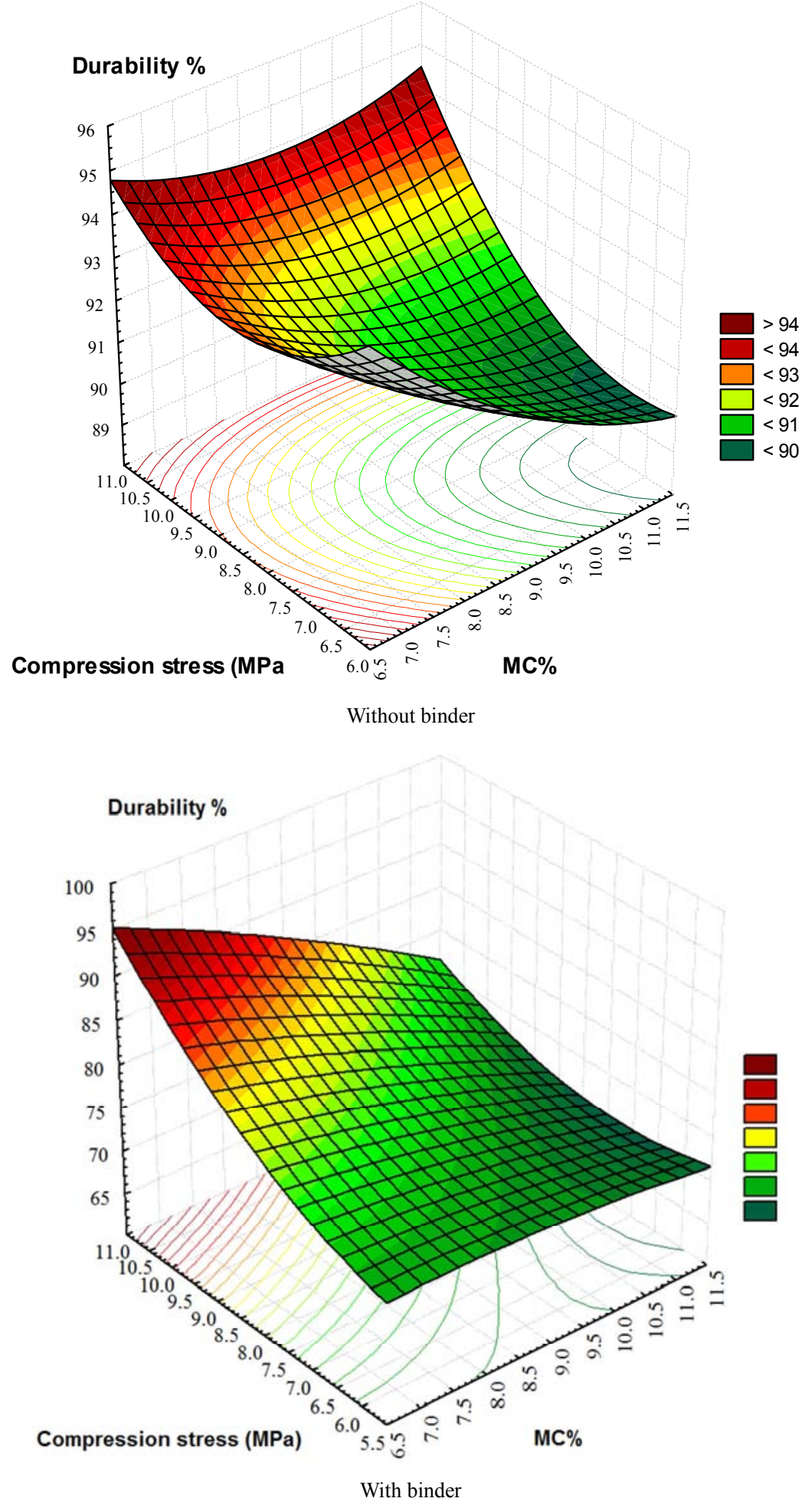

Figure 16b. Effect of moisture content of compression stress and durability for date palm leaflets. 


\subsection{Briquettes Water Resistance}

The relation between water resistance and moisture content for date palm stalks briquettes and date palm leaflets briquettes are shown in Figure 18a and 18b. It can be noticed that, increase moisture content decreased water resistance. The increment percentage of water resistance for date palm briquettes was
$16.17 \%$ and $73.53 \%$ during decreasing of moisture content from $8.6 \%$ to $7.5 \%$ and from $10.4 \%$ to $7.5 \%$, respectively, at without binder. While the increment percentage of water resistance for date palm leaflets briquettes $26.19 \%$ and $65.47 \%$ during decreasing of moisture content from $9.23 \%$ to $7.2 \%$ and from $11.2 \%$ to $7.2 \%$, respectively, at without binder.
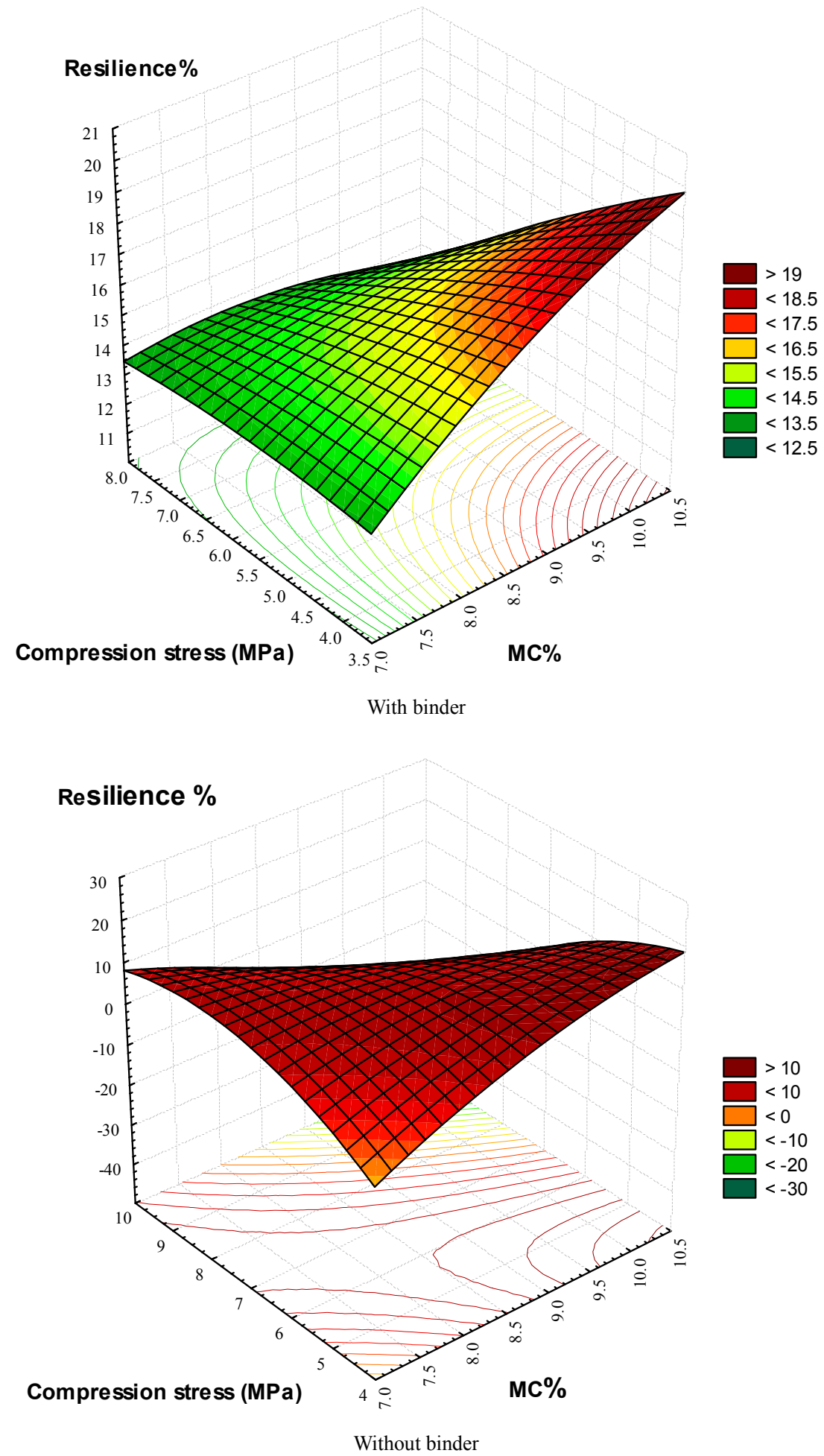

Figure 17a. Effect of moisture content on compression stress and resiliency for date palm stalks (Fronds) briquettes. 

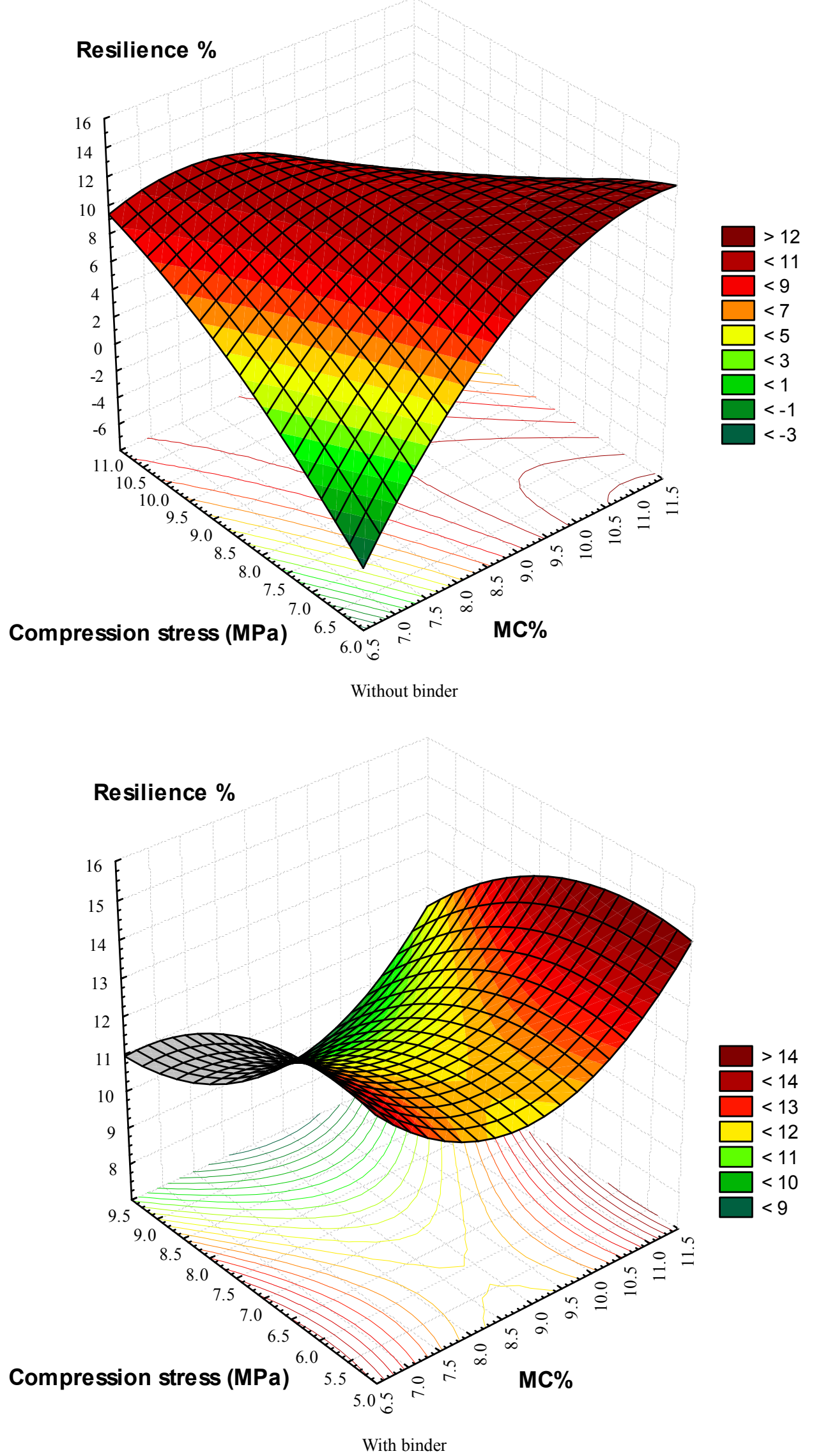

Figure 17b. Effect of moisture content on compression stress and resiliency for date palm leaflets briquettes. 


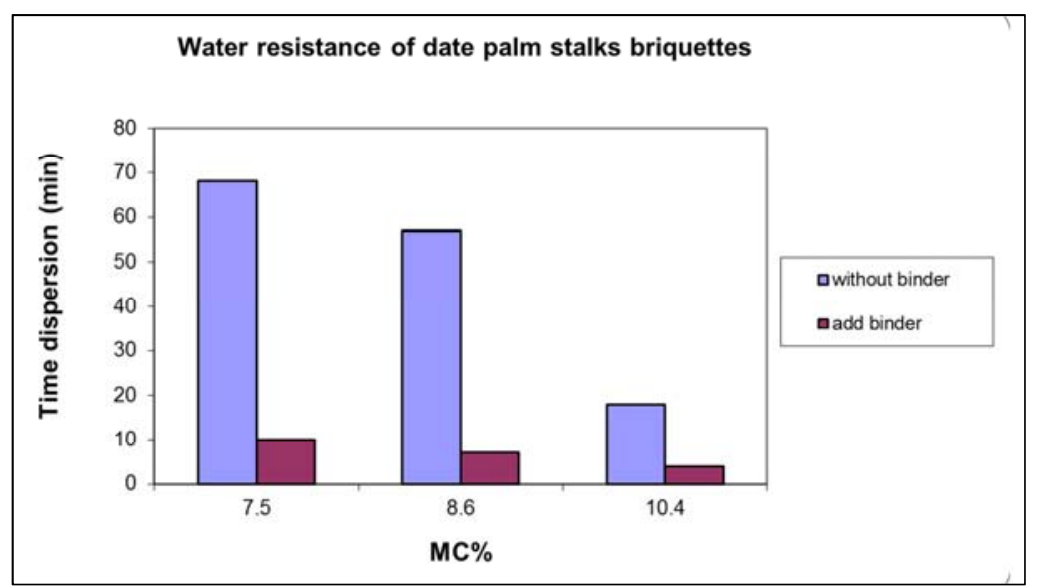

Figure 18a. The relation between moisture content and time dispersion for date palm stalks briquettes.

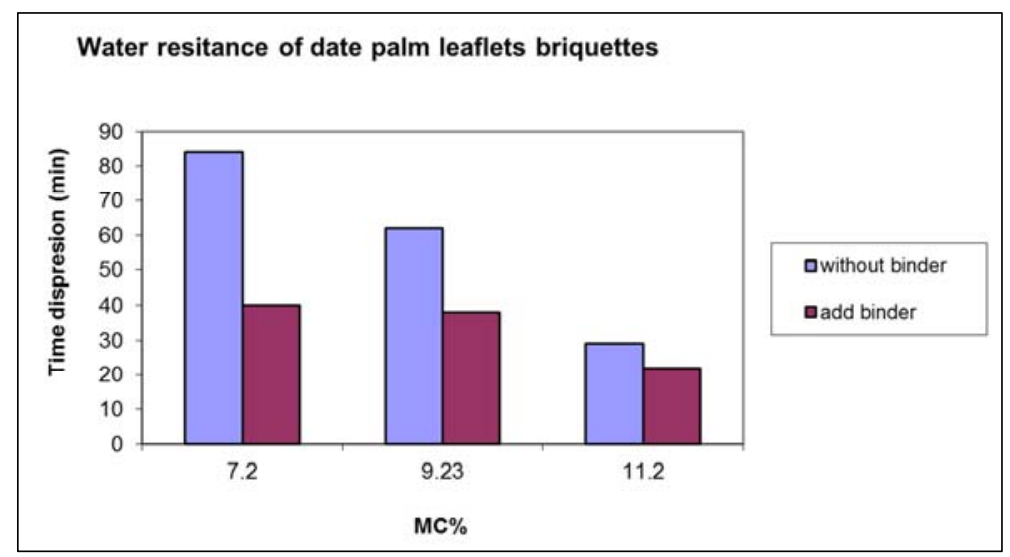

Figure 18b. The relation between moisture content and time dispersion for date palm leaflets briquettes.

\subsection{Effect of Moisture Content on Gases Emission of Date Palm Stalk and Date Palm Leaflets}

The relation between moisture content and gases emissions (CO, CO2, NOx and SO2) for date palm stalk and date palm leaflets (loose and briquettes) as shown in Figure 19a and 19b. It can be noticed that, by increasing of moisture content the gases emissions increase. The gases emitted from date palm stalk and date palm leaflets briquettes were less than stalks loose. Increasing of moisture content from 7.5 to $10.4 \%$ the $\mathrm{CO} 2$ emission increased from $(2.3,1.3$ and $1.8 \%)$ to $(3.1,1.8$, and $2.2 \%$ ) at date palm stalks (loose), date palm stalks briquettes without binder and with binder, respectively, the $\mathrm{CO}$ emission increased from $(0.1297,0.0198$ and $0.0275 \%)$ to $(0.215,0.025$ and $0.0821 \%)$ at date palm stalks (loose) and date palm stalks briquettes without binder and with binder, respectively.

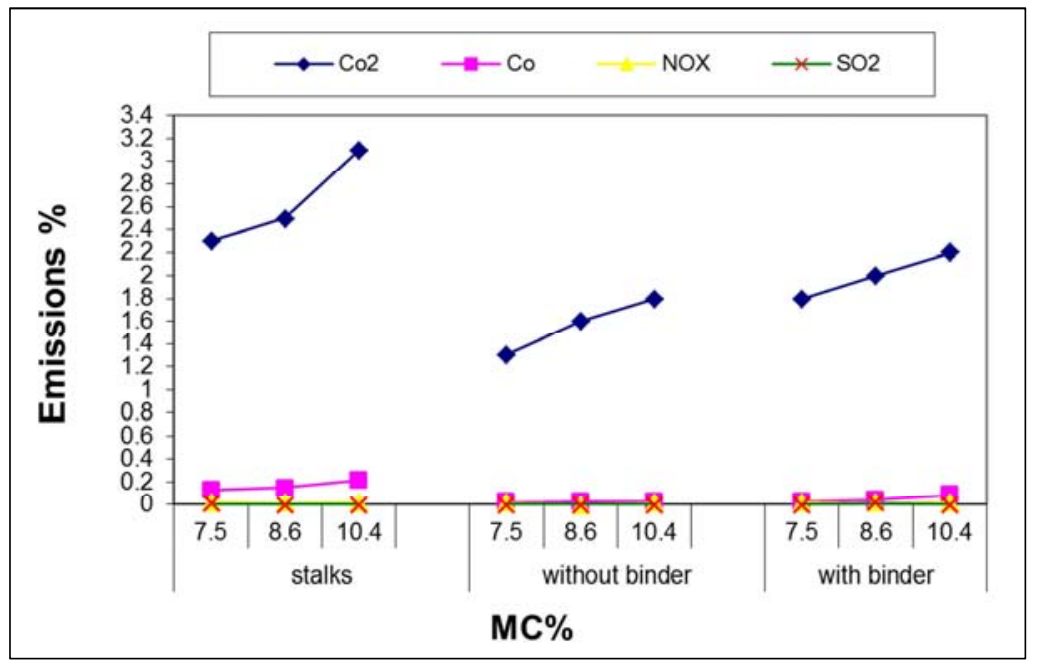

Figure 19a. Effect of moisture content and binder (urea-formaldhyde) on gases emission for date palm stalks (loose and briquettes). 


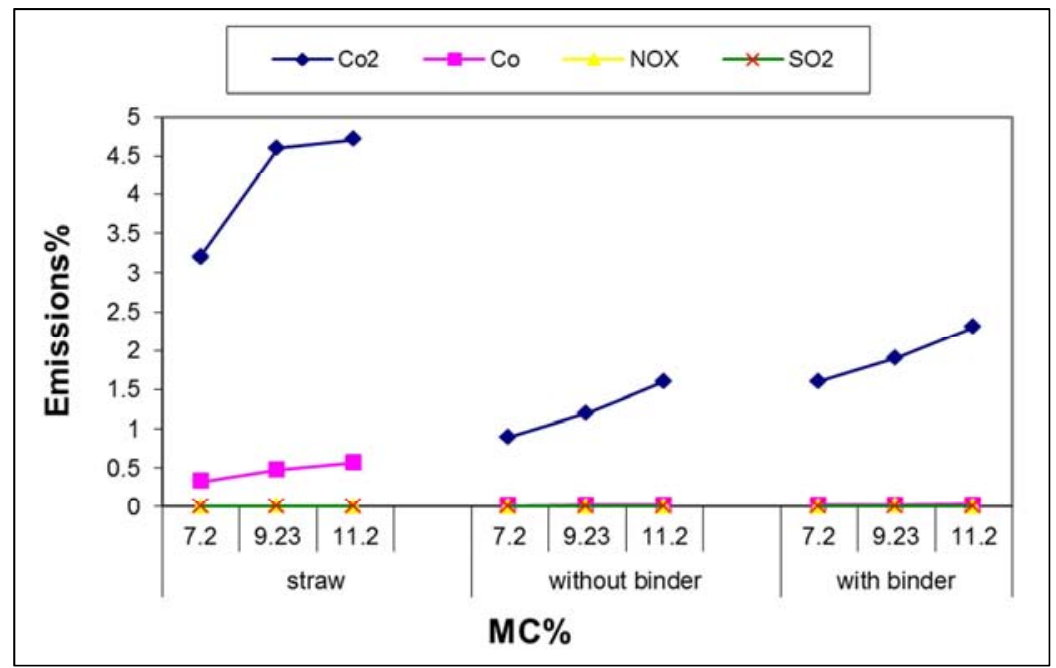

Figure 19b. Effect of moisture content and binder (urea-formaldhyde) on gases emission for date palm leaflets (loose and briquettes).

Increasing of moisture content from 7.2 to $11.2 \%$ the $\mathrm{CO} 2$ emission increased from $(3.2,0.9$ and $1.6 \%)$ to $(4.7,1.6$, and $2.3 \%$ ) at date palm leaflets (loose), date palm leaflets briquettes without binder and with binder, respectively, and the CO emission increased from $(0.324,0.0105$ and $0.018 \%)$ to $(0.5681,0.018$ and $0.032 \%)$ at date palm leaflets (loose), date palm leaflets briquettes without binder and with binder, respectively.

\section{Conclusion}

Densification of biomass materials into briquettes could reduce costs and problems with handling, transportation, storage, and utilization of low bulk density biomass materials. And also, produce good quality (high strength and durability). Moisture content of chopped residuals have a significant impact on the quality of the resulting briquettes the optimum quality properties of the briquettes were 7.5 and $7.2 \%$ moisture content of date palm stalks (Fronds), date palm leaflets, without binder, respectively. the highest compression stress, durability and bulk density were $8.95,10.39 \mathrm{MPa}$, $97.06 \%, 93.64 \%$ and $1.18,0.95$ g.cm-3 for date palm stalks (Fronds), date palm leaflets briquettes, respectively Gases emission $\left(\mathrm{CO}_{2}\right.$ and $\left.\mathrm{CO}\right)$ during combustion reduced from date palm stalks (Fronds), date palm leaflets briquettes without binder than the briquettes with binder and date palm stalks (Fronds), date palm leaflets (loose) at each moisture contents.

\section{References}

[1] Agoudjil, B., Benchabaneb, A., Boudennec, A., Ibos, L. and Fois, M. (2011). Renewable Materials to Reduce Building Heat Loss: Characterization of Date Palm Wood. Energy Build. 43: 491-497.

[2] Al-Sulaiman F. A. (2003). Date palm fiber reinforced composite as a new insulating material, International Journal of Energy Research 27 (14):1293-1297.

[3] Amer Eissa A. H.; Gomaa A. H.; Baiomy M. H. and Ibrahim A.
A. (2008). Physical and Mechanical characteristics for some agricultural residues. Misr j. Ag. Eng., 25 (1): 121-146.

[4] ASAE Standards (2003) American Society of Agricultural Engineers. "Standards Engineers practices Data".

[5] Baliga, M. S., Baliga, B. R. V., Kandathil, S. M., Bhat, H. P., Vayalil, P. K., 2011. A review of the chemistry and pharmacology of the date fruits (Phoenix dactylifera L.). Food Res. Int. 44, 1812-1822.

[6] Chattopadhyay, P. S.; and K. P. Pandy (1999). "Mechanical properties of sorghum stalk in relation quasi-static deformation". J. Agri. Eng. Res. 73: 199-206.

[7] Debdoubi, A.; A. El-amarti.; and E. Colacio (2005) "Production of fuel briquettes from esparto partially pyrolyzed". Energy Conversion and Management, 46, 18771884.

[8] Demirbas, A. (2000) "Conversion of biomass to a pyrolytic oil for blending gasoline as an alternative fuel in internal combustion engines". Energy Sources; 23:553-62.

[9] Dubey, A. K.; P. Chandra.; D. Padhee.; and S. Gangil (2007) "Energy from Cotton Stalks and other Crop Residues". Cotton Advisory Board, 2007.

[10] FAOSTAT (2011). On-Line Statistical Database of the Food and Agricultural Organization of the United Nations, Available online at http://apps.fao.org.

[11] Fasina, O. O. (2008). "Physical properties of peanut hull pellets". Bioresource Technology, 99, 1259-1266.

[12] Gibiiz, B.; and U. S. Kucukbayrak (1996) "Briquetting of Istanbul-Kemerburgaz lignite of Turkey". Fuel Processing Technology, 47, 111-118.

[13] Jha, S. K.; A. Singh.; and A. Kumar (2008) "Physical characteristics of compressed cotton stalks". Biomass Engineering, 99, 205-210.

[14] Mc Mullen, J.; O. O. Fasina.; C. W. Wood.; and Y. Feng (2005). "Storage and handling characteristics of pellets from poultry litter". Applied Engineering in Agriculture, 21, 645-51.

[15] Nalladurai, K.; and R. V. Morey (2009) "Factors affecting strength and durability of densified biomass products". Biomass and Bio-energy, 33, 337-359. 
[16] Nalladurai, K.; and R. V. Morey (2010) "Natural binders and solid bridge type binding mechanisms in briquettes and pellets made from corn Stover and switchgrass". Bioresource Technology, 101, 1082-1090.

[17] Panwar, V.; B. Prasad.; and K. L. Wasewar (2011) "Biomass Residue Briquetting and Characterization". J. Energy Eng.-ASCE 137, 108-114.

[18] Shaban, D. A.; and O. M. Sawan (2010). "The Utilization of Agricultural Waste as One of the Environmental Issues in Egypt (A Case Study)". Journal of Applied Sciences Research, 6 (8): 1116-1124.

[19] Stahl, M.; K. Granstrom.; J. Berghel.; and R. Renstrom (2004). "Industrial processes for biomass drying and their effects on the quality properties of wood pellets". Biomass and Bioenergy 27 , 621-628.

[20] Werther, J.; M. Saenger.; E. U. Hartge.; T. Ogada.; and Z. Siagi (2000) "Combustion of agricultural residues". Prog. Energ. Combust Sci, 26, 1-27.

[21] Yamnan, S.; M. SahanŞahan.; H. Haykiri-Açma.; K. Şeşen.; and S. Küçükbayrak (2001) "Fuel briquettes from biomass-lignite blends". Fuel Process Technol, 72, 1-8.

[22] Yassine El may, Mejdi Jeguirim, Sophie Dorge, Gwenaelle Trouvé, Rachid Said (2013) Experimental investigation on gaseous emissions from the combustion of date palm residues in laboratory scale furnace Original. Bioresource Technology, Volume 131, Page 94. 